\title{
Calorimetry of dehydrogenation and dangling-bond recombination in several hydrogenated amorphous silicon materials
}

\author{
P. Roura, ${ }^{1}$ J. Farjas,${ }^{1}$ Chandana Rath, ${ }^{1,2}$ J. Serra-Miralles, ${ }^{1}$ E. Bertran, ${ }^{3}$ and P. Roca i Cabarrocas ${ }^{4}$ \\ ${ }^{1}$ GRMT, Department of Physics, University of Girona, Campus Montilivi, Edif.PII, E17071-Girona, Catalonia, Spain \\ ${ }^{2}$ School of Materials Science and Technology, Institute of Technology, Banaras Hindu University, Varanasi, India \\ ${ }^{3}$ FEMAN, Departament de Física Aplicada i Optica, Universitat de Barcelona, E08028, Barcelona, Catalonia, Spain \\ ${ }^{4}$ LPICM (UMR 7647 CNRS) Ecole Polytechnique, 91128 Palaiseau Cedex, France
}

(Received 8 July 2005; published 13 February 2006)

\begin{abstract}
Differential scanning calorimetry (DSC) was used to study the dehydrogenation processes that take place in three hydrogenated amorphous silicon materials: nanoparticles, polymorphous silicon, and conventional device-quality amorphous silicon. Comparison of DSC thermograms with evolved gas analysis (EGA) has led to the identification of four dehydrogenation processes arising from polymeric chains $(A), \mathrm{SiH}$ groups at the surfaces of internal voids $\left(A^{\prime}\right)$, $\mathrm{SiH}$ groups at interfaces $(B)$, and in the bulk $(C)$. All of them are slightly exothermic with enthalpies below $50 \mathrm{meV} /(\mathrm{H}$ atoms $)$, indicating that, after dissociation of any $\mathrm{SiH}$ group, most dangling bonds recombine. The kinetics of the three low-temperature processes [with DSC peak temperatures at around $320(A), 360\left(A^{\prime}\right)$, and $430{ }^{\circ} \mathrm{C}(B)$ ] exhibit a kinetic-compensation effect characterized by a linear relationship between the activation entropy and enthalpy, which constitutes their signature. Their $\mathrm{Si}-\mathrm{H}$ bond-dissociation energies have been determined to be $E(\mathrm{Si}-\mathrm{H})_{0}=3.14(A), 3.19\left(A^{\prime}\right)$, and $3.28 \mathrm{eV}(B)$. In these cases it was possible to extract the formation energy $E(\mathrm{DB})$ of the dangling bonds that recombine after $\mathrm{Si}-\mathrm{H}$ bond breaking $\left[0.97(A), 1.05\left(A^{\prime}\right)\right.$, and $\left.1.12(B)\right]$. It is concluded that $E(\mathrm{DB})$ increases with the degree of confinement and that $E(\mathrm{DB})>1.10 \mathrm{eV}$ for the isolated dangling bond in the bulk. After $\mathrm{Si}-\mathrm{H}$ dissociation and for the low-temperature processes, hydrogen is transported in molecular form and a low relaxation of the silicon network is promoted. This is in contrast to the high-temperature process for which the diffusion of $\mathrm{H}$ in atomic form induces a substantial lattice relaxation that, for the conventional amorphous sample, releases energy of around $600 \mathrm{meV}$ per $\mathrm{H}$ atom. It is argued that the density of sites in the Si network for $\mathrm{H}$ trapping diminishes during atomic diffusion.
\end{abstract}

DOI: 10.1103/PhysRevB.73.085203

PACS number(s): 61.43.Dq, 81.15.Gh, 68.60.Dv, 81.05.Gc

\section{INTRODUCTION}

Hydrogen plays a crucial role in the quality of amorphous silicon materials. It reduces the density of dangling bonds and the internal stress of the silicon network, which results in a narrowing of the band tails. These facts improve the electronic and optical properties of hydrogenated amorphous silicon $(a-\mathrm{Si}: \mathrm{H})$ with respect to pure amorphous material. ${ }^{1}$

A number of hydrogen states are known to exist at room temperature and are characterized both by the kind of bonding with the $\mathrm{Si}$ atoms and by their atomic environment: i.e., the monohydride $(\equiv \mathrm{SiH})$ may be isolated, clustered at the surfaces of internal voids, or form platelets in bulk. The most useful technique for the identification of the particular hydrogen states is infrared (IR) absorption spectroscopy. ${ }^{2}$ From their characteristic stretching and bending modes, the isolated monohydride $(\equiv \mathrm{SiH})$, the clustered monohydride $\left[(\equiv \mathrm{SiH})_{n}\right]$, and the dihydride $\left(=\mathrm{SiH}_{2}\right)$ can be distinguished. ${ }^{3,4}$ Recently, a new vibrational mode has been identified and associated with $\mathrm{H}$ atoms located at the interfaces between silicon clusters or nanocrystals and the surrounding amorphous matrix..$^{5,6}$ For the sake of completeness, we must say that molecular hydrogen located in internal voids ${ }^{7}$ or individually trapped in bulk ${ }^{8}$ has been detected by nuclear magnetic resonance.

Hydrogen desorption experiments, monitored by mass spectrometry or by pressure measurements, have tradition- ally been used to detect the hydrogen states. ${ }^{9-12}$ When the material is heated at a constant rate, dehydrogenation peaks (proportional to the hydrogen desorption rate) appear at characteristic temperatures. From these experiments and provided that dehydrogenation is not diffusion controlled, the activation energy of $\mathrm{Si}-\mathrm{H}$ bond breaking can be obtained. The most complete work devoted to this objective is that of Khait et al. ${ }^{13}$ In their paper, the thermal activation of a lowtemperature peak (below $400{ }^{\circ} \mathrm{C}$ ), characteristic of lowquality material, is analyzed. They obtain an activation energy of $1.9 \mathrm{eV}$, consistent with independent experiments on the desorption of hydrogen from the surface of monocrystalline silicon ${ }^{14}$ and with theoretical calculations. ${ }^{15}$ This energy corresponds to the breaking of two neighboring $\mathrm{SiH}$ groups and the simultaneous formation of an $\mathrm{H}$ molecule. From this and other experimental evidence, it is known that this lowtemperature dehydrogenation process is usually associated with clustered $\mathrm{SiH}$ groups on the surface of internal voids. ${ }^{16}$ When dehydrogenation is diffusion controlled, desorption experiments have proven useful for the analysis of the diffusion mechanisms of hydrogen in $a$-Si:H. ${ }^{17,18}$ The results are of special interest when done on device-quality material, where most hydrogen is in the isolated monohydride or clustered states in bulk. In this case, there is broad agreement that hydrogen diffuses in atomic form ${ }^{16,19}$ until it reaches the external surface where it is desorpted as molecular hydrogen.

During dehydrogenation, extensive bond breaking and new bond formation occur, resulting in a thermal signal from 
TABLE I. Chemical composition of the samples studied, hydrogen content $n_{i} / n_{\mathrm{Si}}$ of the $\mathrm{SiH}$ groups determined by EGA, and enthalpy of the corresponding DSC bands per unit mass $\left(Q_{i}\right)$ and per $\mathrm{H}$ atom $\left(E_{i}\right)$ (all processes are exothermic).

\begin{tabular}{|c|c|c|c|c|c|c|c|c|c|c|c|c|c|}
\hline Sample & Composition & $n_{\mathrm{H} A} / n_{\mathrm{Si}}$ & $n_{\mathrm{H} A^{\prime}} / n_{\mathrm{Si}}$ & $n_{\mathrm{H} B} / n_{\mathrm{Si}}$ & $n_{\mathrm{HC}} / n_{\mathrm{Si}}$ & $\begin{array}{l}Q_{A} \\
(\mathrm{~J} / \mathrm{g})\end{array}$ & $\begin{array}{l}Q_{A^{\prime}} \\
(\mathrm{J} / \mathrm{g})\end{array}$ & $\begin{array}{l}Q_{B} \\
(\mathrm{~J} / \mathrm{g})\end{array}$ & $\begin{array}{l}Q_{C} \\
(\mathrm{~J} / \mathrm{g})\end{array}$ & $\begin{array}{c}E_{A} \\
{[\mathrm{meV} /(\mathrm{H} \text { atoms })]}\end{array}$ & $E_{A^{\prime}}$ & $E_{B}$ & $E_{C}$ \\
\hline np19598 & $\mathrm{SiH}_{0.35} \mathrm{O}_{0.25}$ & 0.14 & & 0.21 & & 12 & & 11 & & 48 & & 13 & \\
\hline$n p 2563 \mathrm{~B}$ & $\mathrm{SiH}_{0.53} \mathrm{O}_{0.11}$ & 0.25 & & 0.28 & & 15 & & 46 & & 19 & & 52 & \\
\hline npUA54 & $\mathrm{SiH}_{0.63} \mathrm{O}_{0.33}$ & 0.22 & & 0.40 & & 14 & & 11 & & 20 & & 9 & \\
\hline$n p 598 \mathrm{C}$ & $\mathrm{SiH}_{0.39} \mathrm{O}_{0.28}$ & 0.23 & & 0.16 & & 4.6 & & 24 & & 6 & & 48 & \\
\hline$p m-\mathrm{Si}: \mathrm{H}$ & $\mathrm{SiH}_{0.16}$ & 0.01 & 0.02 & 0.10 & 0.045 & & 3.6 & 18 & 10 & & 52 & 53 & $\approx 40$ \\
\hline$a-\mathrm{Si}: \mathrm{H}$ & $\mathrm{SiH}_{0.12}$ & $10^{-4}$ & $10^{-4}$ a & $10^{-3}$ a & 0.12 & & 1.8 & 2.7 & 430 & & $5 \times 10^{3}$ a & $760^{a}$ & $\approx 700^{\mathrm{a}}$ \\
\hline
\end{tabular}

The real values of these quantities for the $a-\mathrm{Si}: \mathrm{H}$ sample are discussed in the text.

the heat evolved from the material. In contrast with hydrogen desorption experiments (where the signal is detected when the atoms leave the external surface of the material), in calorimetric experiments no delay exists between bond breaking and the thermal signal. So the kinetics of $\mathrm{Si}-\mathrm{H}$ bond breaking and subsequent dangling-bond recombination can be studied directly. On the other hand, the enthalpy of the processes can be calculated from the heat exchanged and the total energy of the $\mathrm{H}$ states and dangling bonds can be deduced. ${ }^{20} \mathrm{Up}$ to now, very few, inconclusive calorimetric studies on dehydrogenation of $a-\mathrm{Si}: \mathrm{H}$ have been published. $^{21-24}$ They were reviewed in Ref. 20. In that paper, we studied the dehydrogenation process occurring at the lowest temperature in $a$-Si:H nanoparticles and compared its kinetics with the results obtained from the desorption experiments reported for $a-\mathrm{Si}: \mathrm{H}$ thin films by Khait et al. ${ }^{13}$ Dangling-bond formation energy of $1.05 \mathrm{eV}$ was obtained and the enthalpy of dehydrogenation was around $50 \mathrm{meV} /(\mathrm{H}$ atoms) (exothermic).

The purpose of this paper is to extend our previous work ${ }^{20}$ to thin films and to analyze all the dehydrogenation processes detected both by calorimetry and by desorption experiments. In addition to amorphous silicon nanoparticles, two kinds of device-quality films have been studied: a conventional amorphous silicon material and a so-called polymorphous silicon material. The interest in polymorphous silicon lies in its improved transport properties ${ }^{25}$ and the lowest density of defects ever obtained in any amorphous silicon material, ${ }^{26}$ allowing the fabrication of $p-i$ - $n$ photodiodes with very low dark-current densities. ${ }^{27}$ Even after light soaking, the density of defects remains lower than in conventional amorphous silicon, ${ }^{25}$ which can produce enhanced photovoltaic conversion efficiency. ${ }^{28}$ The microstructure of polymorphous silicon consists of silicon clusters or nanocrystals embedded in an amorphous matrix ${ }^{29}$ and is similar to other kinds of $a$-Si:H materials grown "on the edge of crystallinity." ${ }^{30}$ Consequently, it can be considered as an intermediate state between silicon nanoparticles and conventional amorphous silicon. In fact, it shares the main $\mathrm{SiH}$ groups encountered in nanoparticles and those found in amorphous silicon. ${ }^{31}$

Comparison of the three materials has allowed us to identify three particular $\mathrm{SiH}$ groups in addition to the main $\mathrm{H}$ state in the bulk of the amorphous Si network. Their bondbreaking kinetics has been characterized, and the enthalpy of all the dehydrogenation processes, the $\mathrm{Si}-\mathrm{H}$ dissociation, and dangling-bond formation energies have been quantified. Finally, the dangling-bond recombination, which occurs after or during dehydrogenation, has been analyzed.

\section{EXPERIMENT}

A number of $a$-Si:H materials were grown by plasmaenhanced chemical vapor-deposition (PECVD). Amorphous silicon nanoparticles $(n p-\mathrm{Si}: \mathrm{H})$ were obtained at room temperature from decomposition of pure silane. The usual growing conditions and structure are described elsewhere. ${ }^{32}$ Typical particle diameters are much smaller than $100 \mathrm{~nm}$. They have a high hydrogen concentration $(>30 \%)$ and a residual amount of oxygen that is incorporated when the reaction chamber is opened to the air. The IR spectra in the bending region contain the 2000-2090 doublet ${ }^{33}$ which is usually attributed to isolated monohydride $\left(2000 \mathrm{~cm}^{-1}\right)$ and $=\mathrm{SiH}_{2}$ groups or $(\equiv \mathrm{Si}-\mathrm{H})_{n}$ on surfaces $\left(2090 \mathrm{~cm}^{-1}\right)$. The intense absorption band in the wagging region of the spectrum $\left(845-910 \mathrm{~cm}^{-1}\right)$ (Ref. 33) indicates the existence of polymeric chains $\left[\left(\mathrm{SiH}_{2}\right)_{n}\right]$.

In addition to the nanoparticles, two films were grown at $250{ }^{\circ} \mathrm{C}$. One corresponds to a device-quality standard material $(a-\mathrm{Si}: \mathrm{H}$ in the rest of the paper), while the other one is a special grade known as polymorphous silicon ( $p m-\mathrm{Si}: \mathrm{H})$. The standard material contains most of the $\mathrm{H}$ atoms as isolated or clustered monohydride in bulk $(\equiv \mathrm{Si}-\mathrm{H})$ whereas in $\mathrm{pm}-\mathrm{Si}: \mathrm{H}$ a detailed analysis of the IR stretching region reveals three states of hydrogen: ${ }^{5}$ isolated and clustered monohydride in bulk $\left(2000 \mathrm{~cm}^{-1}\right)$, hydrogen on surfaces or $=\mathrm{SiH}_{2}$ groups $\left(2080 \mathrm{~cm}^{-1}\right)$, and hydrogen on interfaces $\left(2030 \mathrm{~cm}^{-1}\right)$. The existence of this special state of hydrogen on interfaces results from the particular growing conditions of $\mathrm{pm}$-Si:H. In this material, silicon clusters or nanoparticles are deposited together with $\mathrm{SiH}_{x}$ radicals. ${ }^{34}$ Both films were deposited onto the walls of the reaction chamber for a very long time (deposition time $\approx 10 \mathrm{~h}$ ). The thick deposit of about $10 \mu \mathrm{m}$ was then scratched from the walls and enough material (around $100 \mathrm{mg}$ ) was obtained for the experiments of calorimetry.

The chemical composition of all the samples is detailed in Table I. It has been determined by elementary analysis experiments combined with thermogravimetry (see Ref. 31 for 


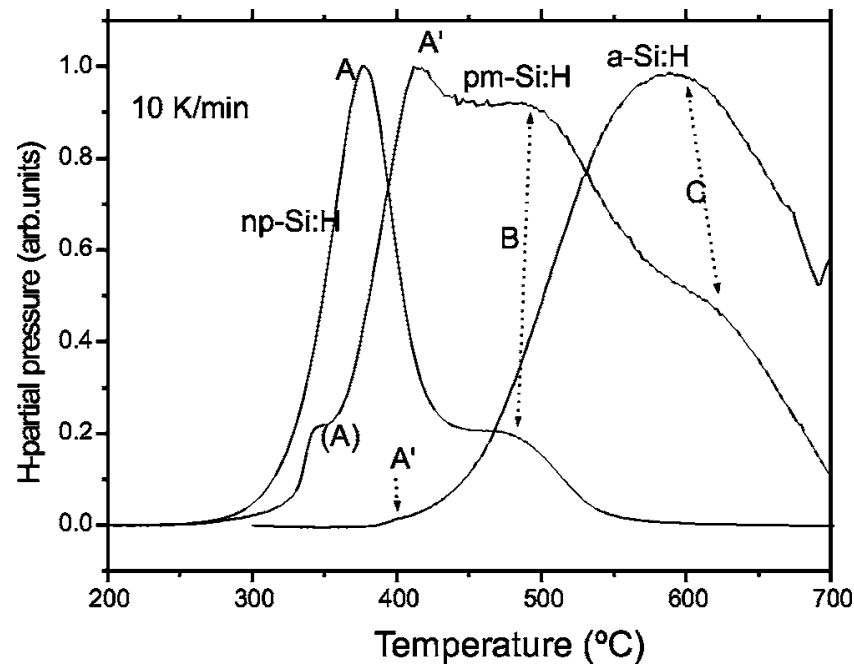

FIG. 1. Gas-evolved analysis (EGA) thermograms measured at $10 \mathrm{~K} / \mathrm{min}$ for the two films and one of the nanoparticles.

details). Calorimetric experiments were carried out in a differential scanning calorimeter (DSC822e of Mettler Toledo) in an inert atmosphere of argon (impurities content $<5 \mathrm{ppm})$. These experiments were programmed at various heating rates $(10,20,40$, and $80 \mathrm{~K} / \mathrm{min})$ up to $700{ }^{\circ} \mathrm{C}$. The sample was then kept at a high temperature to ensure that, during a second heating ramp under the same conditions, no additional structural transformations would occur. This second thermogram was subtracted from the first one in order to correct it for the apparatus baseline. Due to the sensitivity of nanoparticles to low-temperature oxidation, ${ }^{35}$ the sample mass was measured before and after the experiment. If after correction by the mass loss due to dehydrogenation a significant mass gain due to oxidation was detected, the thermogram was rejected. Despite this precaution, the contribution of any residual oxidation to the thermal signal cannot be discarded. Finally, in addition to the standard temperature calibration, the temperature axes have been corrected by the time delay of the apparatus related to the generation of the thermal signal (3 s).

The desorption experiments, henceforth referred to as "evolved gas analysis" (EGA), were performed in a vacuum furnace pumped down to $10^{-6}$ Torr by a turbomolecular pump. The evolved hydrogen molecules were detected by a mass spectrometer whose signal was considered, as usual, ${ }^{16}$ to be proportional to the evolution rate. The heating rate was kept constant at 10 or $40 \mathrm{~K} / \mathrm{min}$.

\section{RESULTS}

\section{A. Evolved gas analysis}

The EGA thermograms obtained at $10 \mathrm{~K} / \mathrm{min}$ (Fig. 1) show several dehydrogenation processes whose relative intensities depend on the material. All thermograms measured up to now on nanoparticles ${ }^{20,32}$ contain a two-peak structure $\left(A\right.$ and $B$ ) with maxima below $500{ }^{\circ} \mathrm{C}$ (around 380 and $480{ }^{\circ} \mathrm{C}$, respectively), the peak at the lowest temperature $(A)$ always being more intense. For the standard material ( $a$

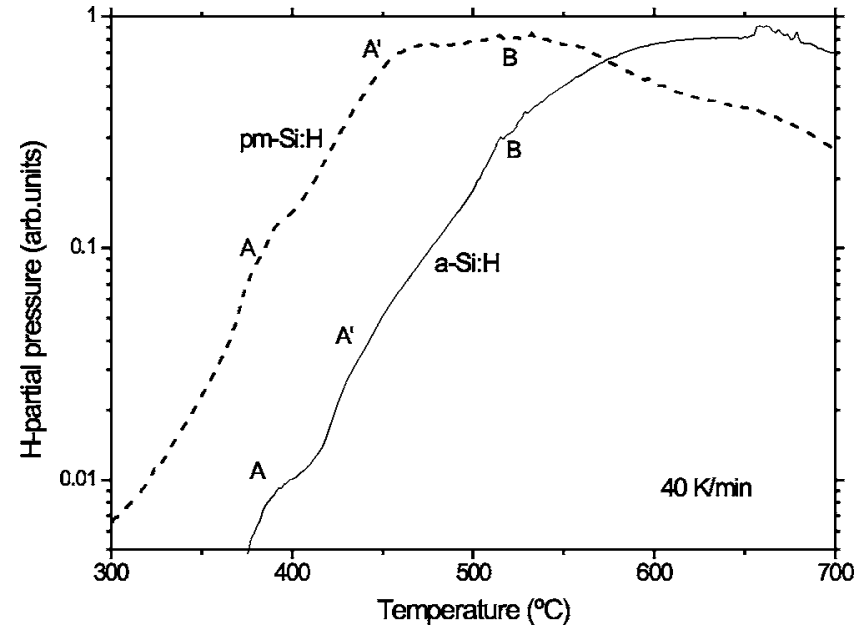

FIG. 2. EGA thermograms measured at $40 \mathrm{~K} / \mathrm{min}$ plotted in logarithmic scale to highlight, in one single curve, the presence of the three minor components $\left(A, A^{\prime}\right.$, and $\left.B\right)$ in the conventional $a$ -Si:H sample (in a linear scale the $A$ and $B$ signals are clearly resolved, too). Note that the structure of the $a-\mathrm{Si}: \mathrm{H}$ thermogram up to $500{ }^{\circ} \mathrm{C}$ is similar to that of the $p m-\mathrm{Si}: \mathrm{H}$ thermogram.

-Si:H), the thermogram is dominated by a high-temperature process centered at $580{ }^{\circ} \mathrm{C}$ (peak $C$ ) and a very weak process at $400{ }^{\circ} \mathrm{C}\left(A^{\prime}\right)$ unlike those in the nanoparticles. (At this point, this is a tentative asignment based on comparison with the thermogram of $p m-\mathrm{Si}: \mathrm{H}$. However, it will become clearer in Sec. IV A, notably with the diagram of Fig. 9.) In polymorphous silicon, the four processes detected in nanoparticles or in $a$-Si:H $\left(A, A^{\prime}, B\right.$, and $\left.C\right)$ make a contribution. In the corresponding thermogram, the first peak $(A)$ is closed in brackets because, as opposed to the other processes, we do not have any independent proof for this assignation. When the experiments are done at $40 \mathrm{~K} / \mathrm{min}$, the minor contributions of the $A, A^{\prime}$, and $B$ processes are also detected for the $a$-Si:H sample (Fig. 2). That is, all the dehydrogenation processes detected in $\mathrm{pm}-\mathrm{Si}: \mathrm{H}$ are also present in the standard material, although they are much less intense. The deconvolution of these EGA thermograms gives the amount of hydrogen atoms released by the material for each process which does not depend significantly on the heating rate (40 or $10 \mathrm{~K} / \mathrm{min}$ ). The mean values are detailed in Table I.

\section{B. Differential scanning calorimetry}

The shape of the DSC thermograms (Fig. 3) is much more complex because, in addition to dehydrogenation, other structural transformations contribute to the thermal signal. In all samples, the DSC thermograms consist of several peaks superimposed on a continuous signal. In the whole temperature range, this signal is always exothermic. A similar continuous heat release was also detected in silicon materials amorphized by ionic implantation, ${ }^{36}$ where it was interpreted as due to structural relaxation. Although the exact microscopic processes have not yet been clarified, ${ }^{37}$ structural relaxation means that the progressive changes in the covalent network of silicon atoms lead to a more relaxed, less energetic, structure. From Fig. 3 it is clear that these relaxation 


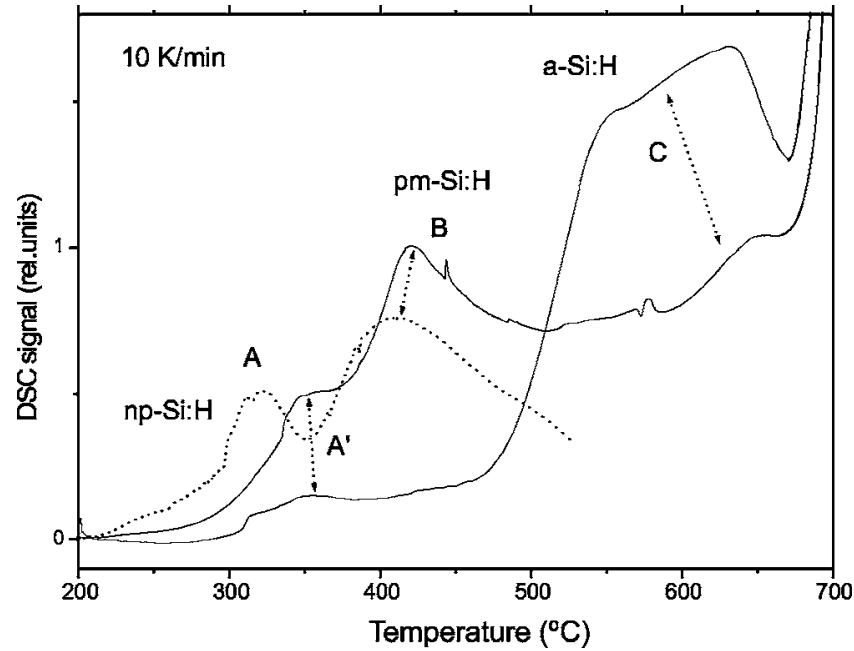

FIG. 3. Differential scanning calorimetry (DSC) thermograms measured at $10 \mathrm{~K} / \mathrm{min}$ for the two films and one of the nanoparticles.

processes are much more active in $p m-\mathrm{Si}: \mathrm{H}$ than in $a$ -Si: $\mathrm{H}$ below $500{ }^{\circ} \mathrm{C}$.

Concerning the dehydrogenation of nanoparticles, the two-peak structure detected by EGA in the nanoparticles has its counterpart in the DSC thermogram. The main difference is that the DSC peaks appear at a lower temperature. This means that there is a significant delay between the processes of $\mathrm{Si}-\mathrm{H}$ bond breaking and the rearrangement of bonds (responsible for the thermal signal) and the evolution of the hydrogen molecules at the outer surfaces of the sample (the EGA signal).

For polymorphous silicon, a very pronounced exothermic peak corresponding to the $B$-dehydrogenation process is detected. A weaker peak, related to the $A^{\prime}$ process, is less evident and can be identified because it appears at a very similar temperature in the DSC curve of the standard $a-\mathrm{Si}: \mathrm{H}$ (Fig. $3)$. This coincidence is even clearer in the experiments done at $80 \mathrm{~K} / \mathrm{min}$ (Fig. 4). All these DSC peaks are "advanced" compared to their EGA counterparts. Concerning the hightemperature desorption process $C$, it makes a very low contribution to the DSC thermogram of polymorphous silicon that can only be identified after comparison with the $a$ $-\mathrm{Si}: \mathrm{H}$ thermogram.

For the standard material, peaks $A^{\prime}$ and $B$ have been detected (Figs. 3 and 4). However, the most relevant feature in its DSC thermogram at $10 \mathrm{~K} / \mathrm{min}$ is the high intense exothermic band beginning at $480{ }^{\circ} \mathrm{C} \mathrm{(Fig.} \mathrm{3).} \mathrm{This} \mathrm{threshold} \mathrm{is}$ similar to that of the EGA signal, indicating that it is due to process $C$ and that, for this particular process, no delay exists between hydrogen desorption and its thermal signal.

The heat released per gram of sample during each dehydrogenation process $\left(Q_{i}\right)$ has been quantified from the peak areas and has been normalized $\left(E_{i}\right)$ to the number of hydrogen atoms obtained from the EGA experiments. The results are summarized in Table I, where the values quoted are the average of the enthalpies obtained at several heating rates. The enthalpy of dehydrogenation per hydrogen atom is very low $(<50 \mathrm{meV})$ for nanoparticles and polymorphous silicon,

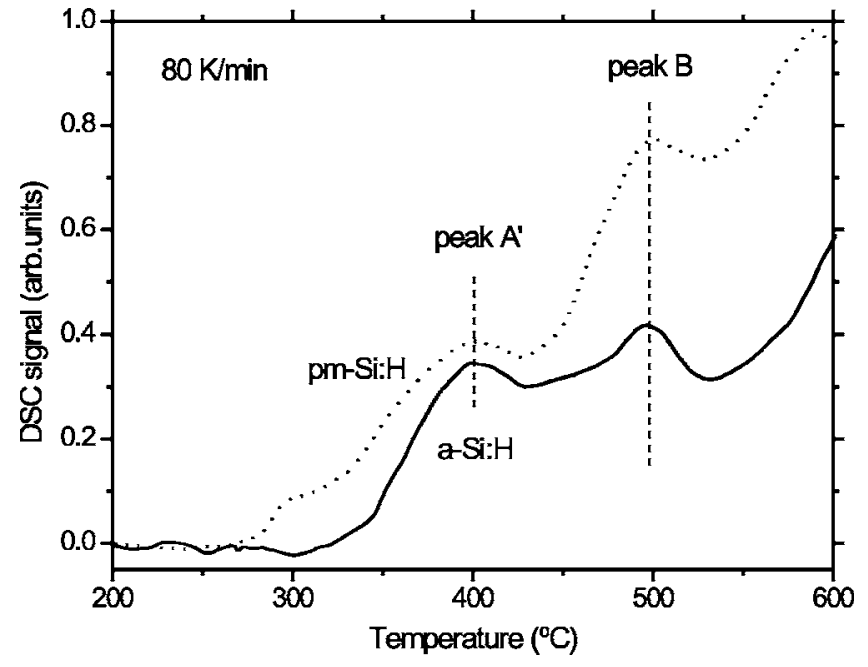

FIG. 4. DSC thermograms measured at $80 \mathrm{~K} / \mathrm{min}$ where the exothermic bands related to $A^{\prime}$ and $B$ dehydrogenation processes are clearly detected in the films.

but much higher for the standard material. In fact, $a-\mathrm{Si}: \mathrm{H}$, $E_{A^{\prime}}$ has an unrealistic value of about $5 \mathrm{eV}$.

In order to analyze the kinetics of dehydrogenation, DSC thermograms have been recorded at $\beta=10,20,40$, and $80 \mathrm{~K} / \mathrm{min}$. The peak temperatures $\left(T_{M}\right)$ have been extracted after subtraction of the continuous signal due to structural relaxation. Typical results are shown in Fig. 5 (peak $B$ of $p m-\mathrm{Si}: \mathrm{H}$ ) and Fig. 6 (peak $B$ of $n p-\mathrm{Si}: \mathrm{H}$ ). The dependence of peak temperatures on heating rate is collected in the Kissinger plots of Figs. 7 and 8 where the $Y$ axis $\left(\beta / T_{M}^{3}\right)$ is chosen for further analysis (Sec. IV A).

For the $A, A^{\prime}$, and $B$ peaks, the relative variations of enthalpy among different heating rates can be as high as $50 \%$ of the maximum value (Fig. 5). It is worth noting that, at the heating rates given in Fig. 5, the peaks are very reproducible and their areas can be quantified with an error bar of $\pm 5 \%$. So the differences among the enthalpies obtained at several

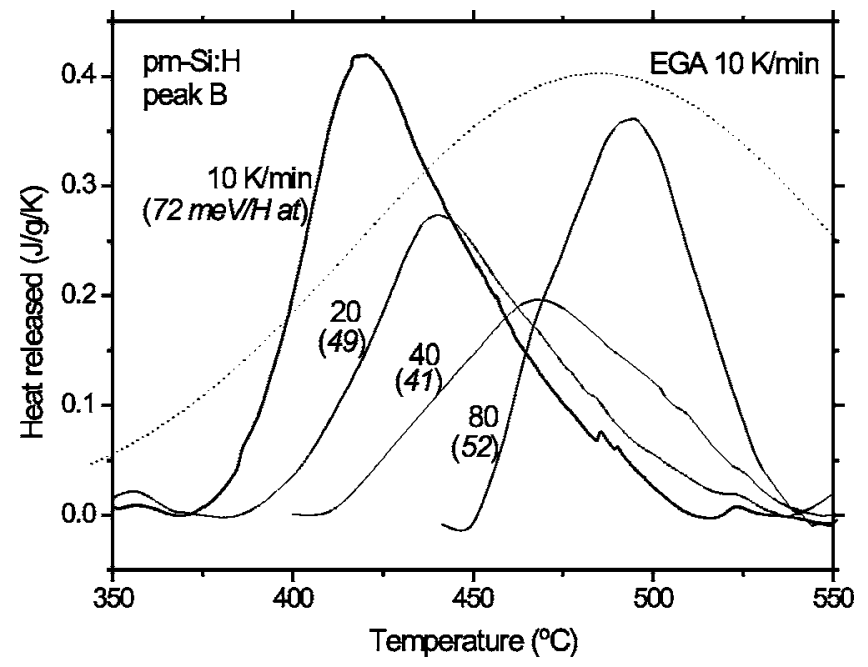

FIG. 5. Thermal activation of the DSC band related to process $B$, measured in the polymorphous sample. The dotted line is the $B$ component of the EGA thermogram measured at $10 \mathrm{~K} / \mathrm{min}$. 


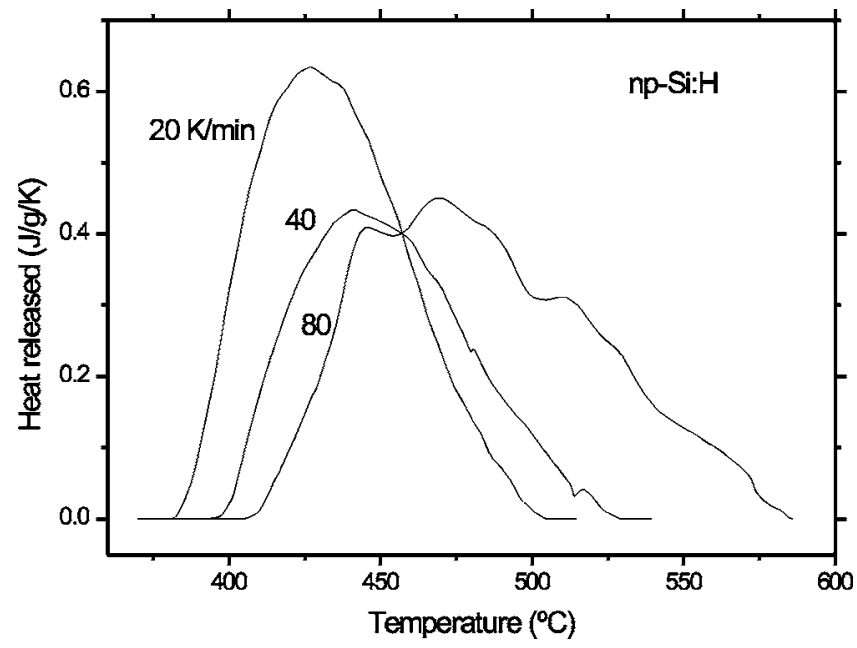

FIG. 6. Thermal activation of the DSC band related to process $B$ in one of the nanoparticles.

heating rates and for different samples (Table I) are significant.

For completeness, we can say that no thermal signal corresponding to process $A$ has been detected in the films and that the threshold appearing at $680{ }^{\circ} \mathrm{C}$ corresponds to crystallization. ${ }^{31}$

\section{ANALYSIS AND DISCUSSION}

\section{A. Identification of the dehydrogenation processes}

Up to now, the labels we have assigned to the dehydrogenation bands on the EGA and DSC thermograms $\left(A, A^{\prime}, B\right.$, and $C$ ) are tentative. In fact, this assignation relies on the order in which they appear as the temperature is raised. However, if their position does not coincide for different samples, one may wonder if the dehydrogenation processes are really the same. This is the case, for instance, for peak $B$ in the DSC thermograms of nanoparticles and polymorphous silicon (Fig. 3). On the other hand, in view of the similarity

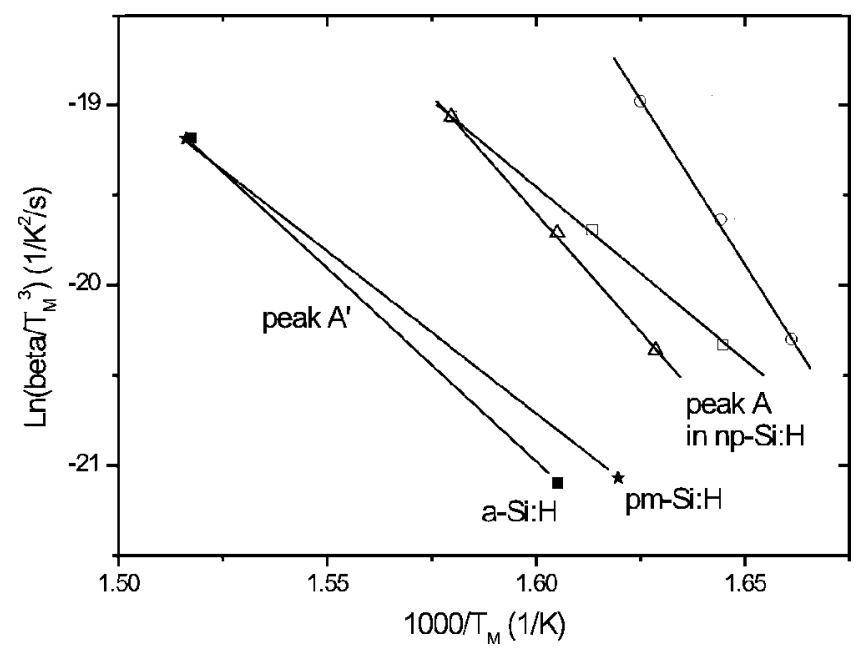

FIG. 7. Kissinger plot for the $A$ and $A^{\prime}$ peaks from which the activation entropies and enthalpies can be obtained.

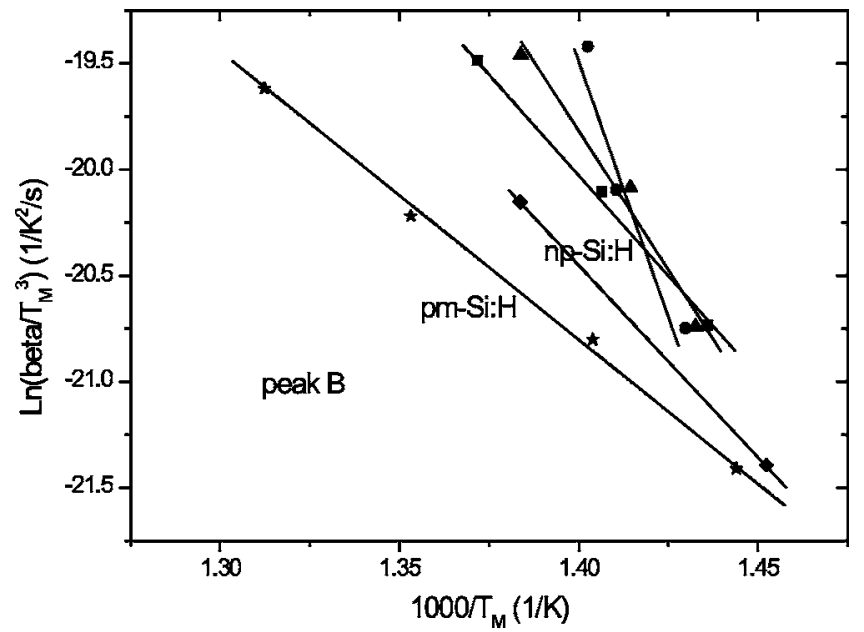

FIG. 8. Kissinger plot for the $B$ peak from which the activation entropies and enthalpies can be obtained.

between these two thermograms below $500{ }^{\circ} \mathrm{C}$, one might think that, in fact, peak $A^{\prime}$ in $p m-\mathrm{Si}: \mathrm{H}$ should be labeled $A$, as in nanoparticles. Another important question is the correspondence of the processes we have detected with those already reported in the literature. In view that apart from the enthalpies obtained for the standard material (Table I) all the enthalpies are very similar, peak identification will rely on their thermal activation. In other words, in principle the position in one single thermogram (DSC or EGA) is not sufficient for the purpose of peak identification. One must measure, instead, how the peak shifts to higher temperature when the heating rate is increased.

If we compare the signal of the dehydrogenation processes measured at the same heating rate $(10 \mathrm{~K} / \mathrm{min})$ by DSC (Fig. 3) and EGA (Fig. 1), we realize that, apart from process $C$, the peak positions are always shifted to higher temperatures in the EGA thermograms. For all peaks, the shift is larger than $50{ }^{\circ} \mathrm{C}$. The thermal signal is measured at the time where the $\mathrm{Si}-\mathrm{H}$ bond breaking and bond rearrangement occur whereas the hydrogen molecules are detected (EGA signal) when they reach the mass spectrometer. Consequently, the delay of the EGA signal with respect to the DSC signal indicates that once the $\mathrm{Si}-\mathrm{H}$ bond is broken, the hydrogen atoms or molecules diffuse for a long while before they reach the external surfaces of the sample. In other words, the EGA thermograms measured in our experiments are diffusion controlled and their thermal activation cannot be used to extract the activation parameters of the $\mathrm{Si}-\mathrm{H}$ bond-breaking processes. For this purpose, the DSC signal must be used instead. Peak identification will rely on the activation parameters thus deduced.

We take as reference the low-temperature desorption process already analyzed in $a-\mathrm{Si}: \mathrm{H}$ films, ${ }^{13,16}$ and we consider a first-order reaction kinetics

$$
\frac{d n_{i}}{d t}=-K_{i} n_{i}
$$

where $n_{i}$ is the number of $\mathrm{H}$ atoms in a particular $\mathrm{SiH}$ group $\left(i=A, A^{\prime}, B\right)$ and $K_{i}$ is the rate constant. $K_{i}$ is thermally acti- 
TABLE II. Thermal activation parameters of the low-temperature dehydrogenation processes (activation entropy $\Delta S$ and enthalpy $\Delta E$ ).

\begin{tabular}{|c|c|c|c|c|c|}
\hline \multirow[b]{2}{*}{ Sample } & \multirow[b]{2}{*}{ Composition } & \multicolumn{2}{|c|}{ Peak $A$ or $A^{\prime}$} & \multicolumn{2}{|r|}{ Peak $B$} \\
\hline & & $\Delta E(\mathrm{eV})$ & $(\mathrm{meV} / \mathrm{K})$ & $\Delta E(\mathrm{eV})$ & $\Delta S \quad(\mathrm{meV} / \mathrm{K})$ \\
\hline np19598 & $\mathrm{SiH}_{0.35} \mathrm{O}_{0.25}$ & & & 1.49 & -0.89 \\
\hline$n p 2563 \mathrm{~B}$ & $\mathrm{SiH}_{0.53} \mathrm{O}_{0.11}$ & 1.68 & -0.19 & 1.67 & -0.58 \\
\hline npUA54 & $\mathrm{SiH}_{0.63} \mathrm{O}_{0.33}$ & 2.28 & 0.79 & 2.21 & 0.22 \\
\hline np598C & $\mathrm{SiH}_{0.39} \mathrm{O}_{0.28}$ & 3.14 & 2.33 & 3.95 & 2.74 \\
\hline pm-Si:H & $\mathrm{SiH}_{0.16}$ & 2.03 & 0.26 & 1.15 & -1.41 \\
\hline$a-\mathrm{Si}: \mathrm{H}$ & $\mathrm{SiH}_{0.12}$ & 2.03 & 0.26 & & \\
\hline
\end{tabular}

vated with activation energy $\Delta E_{i}$ and a prefactor $\left(K_{i}^{\prime} T\right)$, proportional to the thermal frequency $\nu_{0}=k T / h$, where $h$ and $k$ are the Planck and Boltzmann constants, respectively. That is,

$$
K_{i}=\left(K_{i}^{\prime} T\right) e^{-\Delta E_{i} / k T}=\frac{k T}{h} e^{\Delta S_{i} / k} e^{-\Delta E_{i} / k T},
$$

where $\Delta S_{i}$ is the activation entropy. $\Delta S_{i}$ and $\Delta E_{i}$ can be obtained from the shift of the peaks to higher temperatures as the heating rate $\beta$ is increased. It can be shown that the peak temperature $T_{M}$ is related to the heating rate $\beta$ according to the formula (see the Appendix)

$$
\ln \frac{\beta}{T_{M}^{3}}=\ln \frac{k K_{i}^{\prime}}{\Delta E_{i}}-\frac{\Delta E_{i}}{k T_{M}},
$$

which is more accurate than the formula used for the analysis of gas desorption from surfaces ${ }^{38}$ because it takes into account that $\nu_{0}$ depends on $T$.

The Kissinger plots of Figs. 7 and 8 allow determination of the $\Delta S_{i}$ and $\Delta E_{i}$ values, which have been collected in Table II. It is apparent that, for the same hydrogen state ( $A$, $A^{\prime}$, or $\left.B\right), \Delta E$ and $\Delta S$ change considerably from sample to sample. According to Refs. 13 and 39, the barrier $\Delta E$ can diminish by the transfer of energy from charge carriers located in the vicinity of the $\mathrm{SiH}$ group or by short-lived large energy fluctuations of single atoms ${ }^{40}$ (kinetic compensation effect). These contributions result in variations of the entropic barrier. So a particular dehydrogenation process is not characterized by a single value of $\Delta E$, but by a set of $(\Delta E$, $\Delta S)$ values that must follow a linear relationship. ${ }^{13}$ In Fig. 9 we see that there is excellent agreement between our experimental points and theory. This constitutes a proof that the $A$ peak corresponds to the same $\mathrm{H}$ state in all nanoparticles and that the $B$ peak is the same state in all the samples.

Additionally, in Fig. 9 the activation parameters of the low-temperature process analyzed by Khait et al. ${ }^{13}$ are plotted for a number of thin films. These films were deposited at low temperature, which resulted in a high density of interconnected voids. For this particular low-temperature process and films, Khait et al. ${ }^{13}$ demonstrated that the EGA signal was not diffusion controlled so that their deduced activation parameters correspond to the reaction kinetics of Eq. (1) and their signature can be directly compared with those of peaks
$A$ and $B$. From Fig. 9 it is clear that the signature of the points of Khait et al. is different. One could think that the shift of the points of Khait et al. with respect, for instance, to the signature of peak $A$ is due to the different fitting methods used to obtain $\Delta E$ and $\Delta S$ (Khait $e t$ al. obtained them from the shape of the EGA peak). We can discard this objection because Costa et al. ${ }^{41}$ analyzed the desorption peak in nanoparticles where the EGA signal was not diffusion controlled and the activation parameters could be obtained from the same procedure as Khait $e t$ al. The corresponding point (error bars smaller than the point itself) has been included in Fig. 9, and it perfectly agrees with the straight line that fits our results on nanoparticles.

Concerning the $A^{\prime}$ peak, only two points (one per thin film) can be plotted in Fig. 9. Their associated straight segments are, in fact, very elongated rhombs which are the loci of the $(\Delta E, \Delta S)$ values corresponding to an uncertainty of

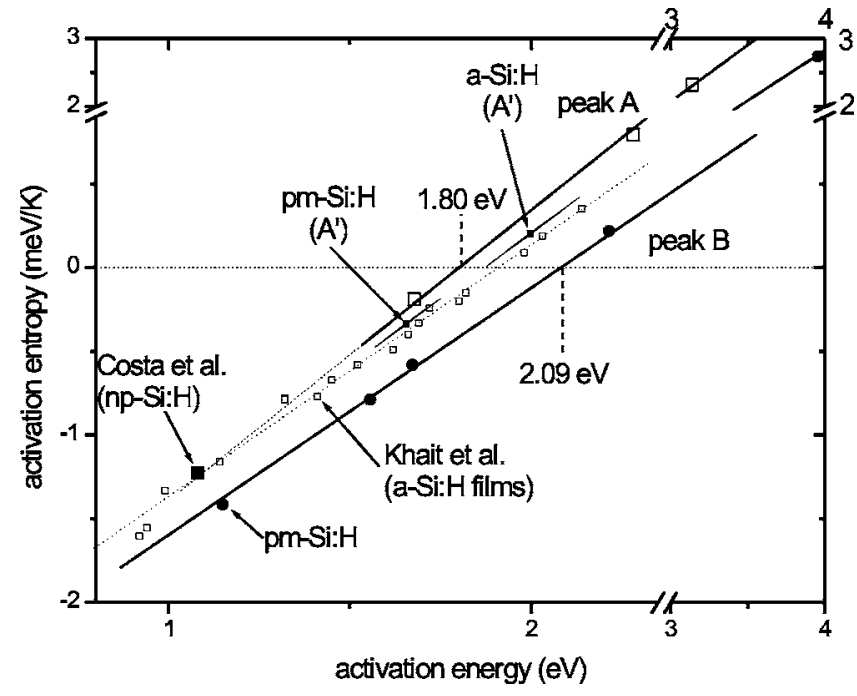

FIG. 9. Signature relating the activation entropies $(\Delta S)$ and enthalpies $(\Delta E)$ for the low-temperature dehydrogenation processes obtained from the thermal activation of the DSC peaks (Figs. 7 and 8 ). The straight segments around points $A^{\prime}$ of our thin films represent the uncertainty in their value. The procedure followed to obtain $(\Delta S, \Delta E)$ for the points of Costa et al. and Khait et al. was different (see text). Note the change of axes used to represent the highest points. 
$\pm 1{ }^{\circ} \mathrm{C}$ in the peak temperature. In this particular Fig. 9 the usual representation of the error bars for the $X$ and $Y$ values is not correct because, according to the Appendix [Eq. (A5)] the constant term of the linear fitting depends on both $\Delta E$ and $\Delta S$ (through $K^{\prime}$ ). The points of peak $A^{\prime}$ for the two thin films are closer to the signature of Khait et al. than that of peak $A$. So we think that peak $A^{\prime}$ in our films corresponds to the same $\mathrm{H}$ state and, consequently, that it is different from the $A$ process detected in nanoparticles. This assignment is reinforced by the existence of the peak detected at the lowest temperature in our films (EGA thermograms of Figs. 1 and 2) which would correspond to peak $A$ in nanoparticles. Unfortunately, the activation parameters of this process cannot be deduced because the corresponding thermal signal has not been detected and, consequently, the bond-breaking kinetics cannot be characterized.

Once it has been established that four different $\mathrm{SiH}$ groups are responsible for the peaks appearing in the EGA and DSC thermograms, one should try to identify their microscopic origin. Peak $C$ has been extensively studied in the literature because it corresponds to the main $\mathrm{SiH}$ group in device-quality material. It comes from desorption of the isolated or clustered monohydride in bulk. ${ }^{17,18}$ The signature of peak $A^{\prime}$ (Fig. 9) had been previously established, ${ }^{13}$ because in the low-quality films studied by Beyer ${ }^{16}$ the EGA signal was not diffusion controlled. According to Beyer, peak $A^{\prime}$ corresponds to $\mathrm{SiH}$ groups located on the surface of internal voids. In contrast with peaks $A^{\prime}$ and $C$, the kinetics of the dehydrogenation processes $A$ and $B$ has not been previously characterized. The main reason is that they are dominant in nanoparticles and polymorphous silicon, respectively, whereas they are almost absent in conventional films. The IR absorption spectra of nanoparticles contain a pronounced doublet at 840 and $910 \mathrm{~cm}^{-1}$ (Ref. 42) related to polymeric $\left(\mathrm{SiH}_{2}\right)_{n}$ groups. ${ }^{43}$ The high hydrogen fraction in this state is confirmed by the appearance of a $2140-\mathrm{cm}^{-1}$ component in the stretching mode attributed to $-\mathrm{SiH}_{3}$ groups, ${ }^{44,45}$ which would terminate the polymer chains. So peak $A$ corresponds to polymer chains. This assignation could not be previously stated ${ }^{20}$ because, at that time, we were not able to obtain the characteristic signature for this process (Fig. 9). Finally, peak $B$ is the dominant process in $p m-\mathrm{Si}: \mathrm{H}$ and it is characteristic of nanoparticles, too. This coincidence is not surprising in view of the particular nanostructure of polymorphous silicon which contains nanoparticles embedded in the amorphous matrix. Additionally, it gives a significant contribution to the EGA thermograms of hydrogenated nanocrystalline silicon. ${ }^{5,46}$ Other authors recorded EGA thermograms similar to that of the polymorphous sample in $a-\mathrm{Si}: \mathrm{H}$ films deposited "on the edge of crystallinity" which contain nanocrystals within the amorphous matrix, too. Although it is not possible to extract the kinetic parameters from their single EGA thermogram, its shape indicates that most of the hydrogen desorpted at low temperature is due to process $B$. Mahan et $a l^{6}$ concluded that "the vast majority of hydrogen is bonded on the surfaces of small crystallites." This assignation is further supported by molecular-dynamics simulations of hydrogen evolution from nanocrystalline silicon ${ }^{47}$ which predict a low-temperature evolution peak at $250-400{ }^{\circ} \mathrm{C}$ (peak $B$ ) in addition to the usual peak of hydrogen in bulk (peak $C$ ). We conclude, then, that peak $B$ corresponds to $\mathrm{SiH}$ groups at the interfaces between nanocrystals or silicon clusters and the surrounding amorphous matrix.

Before leaving this section, we should stress that the signatures of peaks $A$ and $B$ are similar to that of peak $A^{\prime}$ (the series of points from Khait et al. in Fig. 9). In fact, the signature of peak $A^{\prime}$ lies between the other two. So the mechanism of $\mathrm{Si}-\mathrm{H}$ bond breaking should also be similar. In addition, Beyer demonstrated through isotope-labeling experiments ${ }^{13}$ that the low-temperature desorption process in thin films proceeds with the simultaneous formation of a $\mathrm{H}_{2}$ molecule during the dissociation of two neighboring $\mathrm{SiH}$ groups. We can thus assert that hydrogen molecules are formed during the dissociation of any of the low-temperature processes $\left(A, A^{\prime}\right.$, and $\left.B\right)$. This conclusion is reinforced by the values of the dehydrogenation enthalpy (see next section) and will be a key point for further analyses.

\section{B. Enthalpy of dehydrogenation of the low-temperature processes}

Although DSC is the most suitable technique for measuring the enthalpy of structural transformations in amorphous silicon, it has been applied to a very limited extent and, concerning dehydrogenation, the results have been very poor. According to the experiments of Battezzati et al. ${ }^{21}$ the sensitivity of the DSC measuring cell can be greatly perturbed during dehydrogenation due to the high thermal conductivity of the evolved $\mathrm{H}_{2}$. This effect, which would explain the erroneous endothermic signals initially detected on $a-\mathrm{Si}: \mathrm{H}$ films, ${ }^{24,48}$ depends on the physical construction of the DSC and has been shown to be negligible in our apparatus. ${ }^{20} \mathrm{An}$ additional verification has been done with the polymorphous sample, which was measured in another laboratory and gave identical results. ${ }^{49}$

In Table I, the averaged values of the dehydrogenation enthalpies are collected. It is clear that dehydrogenation in amorphous silicon materials is an exothermic process. In fact, apart from the conventional thin film, the enthalpy is very low $[<50 \mathrm{meV} /(\mathrm{H}$ atoms $)]$ and it should be said that dehydrogenation is an isenthalpic process; i.e., the enthalpies of the initial and final states almost coincide.

Our results can be compared with several theoretical calculations of the energetics of various $\mathrm{SiH}$ groups ${ }^{15,50}$ from which the dehydrogenation energy can be obtained if one assumes complete dangling-bond recombination and that hydrogen atoms recombine into a molecule. From the calculations of Allan et al. ${ }^{15}$ on $a-\mathrm{Si}: \mathrm{H}$, slight endothermic energies of $-(0.10-0.14) \mathrm{eV} /(\mathrm{H}$ atoms $)$ for the dehydrogenation of monohydride, dihydride, and neighboring $\mathrm{SiH}$ groups are obtained. From those of Fedders ${ }^{50}$ we obtain $-0.21 \mathrm{eV} /(\mathrm{H}$ atoms) for weakly bonded hydrogen in clusters (from the analysis of Sec. IV F, it can be shown that the dehydrogenation energies at $0 \mathrm{~K}$ are almost equal to the corresponding enthalpies at the dehydrogenation temperature). These theoretical values agree with our results in the sense that they are close to zero too, when compared with the large energies needed for breaking and forming the individual bonds [for instance, $2.26 \mathrm{eV} /(\mathrm{H}$ atoms $)$ for a $\mathrm{H}_{2}$ molecule]. We should 
emphasize, however, that whereas experiments prove that dehydrogenation is exothermic for any of the processes detected, calculations predict endothermic enthalpies. The absolute discrepancies of around $0.2 \mathrm{eV}$ would indicate the reliability of the present theoretical models for predicting the individual energies involved in dehydrogenation.

From this comparison with theoretical predictions (in particular, from the approximate agreement of the enthalpy values and from the fact that the experimental enthalpy is even more exothermic than expected), we can conclude that, after dehydrogenation, a high percentage of the dangling bonds left behind by hydrogen atoms recombine. This conclusion agrees with the measurement of post-hydrogenation levels of dangling bonds. ${ }^{12,51}$ The highest level reported is two orders of magnitude lower than the initial concentration of hydrogen. ${ }^{51}$ Our results give additional evidence of a high level of dangling-bond recombination. If a significant fraction of them survived, then one would expect dependence of the enthalpy on the material microstructure or on the particular $\mathrm{SiH}$ groups being dissociated. The very small absolute differences in the enthalpies of several tens of meV among samples (except for $a-\mathrm{Si}: \mathrm{H}$ ) and among dehydrogenation processes (Table I) exclude this possibility.

Within this context, the variations of enthalpy from sample to sample for the same $\mathrm{SiH}$ group should be analyzed. In the case of nanoparticles, one possible explanation could be the contribution of the low-temperature oxidation process previously reported. ${ }^{35}$ Although special care has been taken, a minor oxidation level could affect the measured enthalpy, owing to its highly exothermic character [9.32 eV/(Si atoms) (Ref. 52)]. However, this explanation can be excluded for the enthalpy variations observed in $\mathrm{pm}$ -Si:H at different heating rates (Fig. 5) because, due to their compact microstructure, oxygen atoms cannot react with the dangling bonds that hydrogen atoms leave behind, far from the external surfaces of the sample (sample thickness around $10 \mu \mathrm{m})$. The enthalpy difference of $31 \mathrm{meV}$ between the $B$ peaks measured at 10 and $40 \mathrm{~K} / \mathrm{min}$ in $\mathrm{pm}-\mathrm{Si}: \mathrm{H}$ (Fig. 5) could be accounted for by a small difference of around 3\% in the level of dangling-bond recombination [we take a dangling-bond recombination energy of $1.05 \mathrm{eV}$ (Ref. 20)]. However, another explanation is possible. The high level of dangling-bond recombination deduced from the value of the enthalpy requires that these defects move through the silicon covalent network. On their way, a degree of bond rearrangement is possible, leading to a diminution of the elastic energy stored in the strained bonds. In other words, dangling-bond recombination will promote a (limited) degree of lattice relaxation, which would release less than $30 \mathrm{meV} /(\mathrm{H}$ atoms $)$.

In summary, we can say that, from the values of the dehydrogenation enthalpy of peaks $A, A^{\prime}$, and $B$, the state after the bond-breaking and rearrangement processes responsible for the thermal signal (i.e., the state just after the DSC peak) is a $\mathrm{H}_{2}$ molecule and a reconstructed silicon network with most dangling bonds recombined and with lower elastic energy. Thus, the measured enthalpy is the result of a number of contributions:

$$
E_{i}=\frac{E(\mathrm{H}-\mathrm{H})_{T}}{2}-E_{i}(\mathrm{Si}-\mathrm{H})_{T}+\eta E(\mathrm{DB})+E_{\text {relax }},
$$

where $E(\mathrm{H}-\mathrm{H})_{T}$ is the dissociation enthalpy of hydrogen, $E_{i}(\mathrm{Si}-\mathrm{H})_{T}$ is the dissociation enthalpy of the $\mathrm{Si}-\mathrm{H}$ bond, and $E(\mathrm{DB})$ is the dangling-bond recombination energy. All these quantities are positive and are given at the temperature $T$ of the DSC peak. $E_{\text {relax }}$ is a minor contribution due to lattice relaxation, and from the analysis, it is clear that coefficient $\eta$ is close to 1 .

Before passing to the next section, we should emphasize that in $a$-Si: $\mathrm{H}$ materials most dangling bonds recombine after $\mathrm{Si}-\mathrm{H}$ bond breaking. This is in contrast with the hydrogen desorption process from the surfaces of crystalline silicon, where the dangling bonds survive. ${ }^{53}$ This difference is not currently appreciated and has led to the consideration that dehydrogenation in amorphous silicon is also an endothermic process. ${ }^{48}$ The eventual measurement of exothermic peaks would be related to the "relaxation" (including dangling-bond recombination) of the silicon network after dehydrogenation. Given that extensive and rapid (see Sec. V $\mathrm{G})$ dangling-bond recombination occurs after $\mathrm{Si}-\mathrm{H}$ bond breaking, we consider that it is more adequate to say that dehydrogenation in amorphous silicon is a slightly exothermic process.

\section{C. $\mathrm{H}_{2}$ trapped in conventional $\boldsymbol{a}-\mathrm{Si}: \mathrm{H}$ and the real values of $\boldsymbol{n}_{\mathrm{H} \boldsymbol{A}^{\prime}}$ and $\boldsymbol{n}_{\mathrm{H} B}$}

The analysis of the previous section is valid for the lowtemperature desorption processes $\left(A, A^{\prime}\right.$, and $\left.B\right)$ in all samples except for the conventional material. In the $a-\mathrm{Si}: \mathrm{H}$ sample, an unrealistic enthalpy of $5 \mathrm{eV}$ is obtained for peak $A^{\prime}$ and a high value of $760 \mathrm{meV}$ is deduced for peak $B$ (Table I). In fact, the heat exchanged per unit mass $\left(Q_{i}\right)$ is quite low and high enthalpies result because the amount of $\mathrm{H}$ atoms detected by EGA for the $A^{\prime}$ and $B$ processes are very low $\left(n_{\mathrm{H}} / n_{\mathrm{Si}}=10^{-4}\right.$ and $10^{-3}$, respectively).

The simplest explanation of this discrepancy is that most of the $\mathrm{H}_{2}$ molecules resulting from the $A^{\prime}$ and $B$ processes remain trapped in internal voids and cannot escape to (or be detected at) the external sample's surface. In other words, the values of $n_{A^{\prime}}$ and $n_{B}$ for the $a$-Si: $\mathrm{H}$ sample quoted in Table I underestimate the real concentration of these $\mathrm{H}$ states in the material and, consequently, the deduced enthalpy per $\mathrm{H}$ atom results in being unusually large. According to this interpretation, it is possible to obtain the real concentration of the $A^{\prime}$ and $B \mathrm{SiH}$ groups in the conventional material by simply taking the enthalpy of peaks $A^{\prime}$ and $B$ of the polymorphous sample as reference $\left(E_{A^{\prime}} \approx E_{B} \approx 50 \mathrm{meV}\right)$. The result is $n_{\mathrm{H}} / n_{\mathrm{Si}}=1 \times 10^{-2}$ and $1.5 \times 10^{-2}$ for the $A^{\prime}$ and $B$ peaks, respectively. Although this concentration is small compared with the total hydrogen content of the conventional sample $\left(12 \times 10^{-2}\right)$, it indicates that a significant fraction (around $20 \%$ ) of the hydrogen atoms reside on the surface of internal voids and on interfaces. Finally, note that the real values of $n_{A^{\prime}}$ and $n_{B}$ are much larger than those reported in Table I (obtained from EGA), which reveals that around $99 \%$ and $95 \%$ of the atoms released after dissociation of the $A^{\prime}$ and $B$ 
$\mathrm{SiH}$ groups remain trapped in the $a-\mathrm{Si}: \mathrm{H}$ sample, respectively.

The presence of hydrogen molecules in the internal voids of amorphous silicon can be detected by NMR. ${ }^{7}$ Their concentration was measured after isothermal annealing, and it was shown to increase at the temperatures where the main $\mathrm{SiH}$ groups began to dissociate. ${ }^{54}$ However, one cannot say properly that, in those experiments, the $\mathrm{H}_{2}$ molecules were effectively trapped. Their detection could simply indicate the delay between $\mathrm{SiH}$ dissociation and hydrogen evolution which is evident in our experiments from the delay between the DSC and EGA peaks.

In contrast with the conventional material, the similarity between the value of the enthalpy of peak $B$ and those obtained in nanoparticles indicate that in polymorphous silicon the $\mathrm{H}_{2}$ molecules do not become trapped. So in its microstructure there are paths for the easy transport of molecular hydrogen to the external surface.

\section{State of hydrogen after $\mathrm{Si}-\mathrm{H}$ bond breaking: Diffusion of $\mathrm{H}_{2}$ molecules}

Up to now, we have assumed that, for the low-temperature desorption peaks, the bond-breaking and rearranging processes leading to the thermal signal result in the formation of a $\mathrm{H}_{2}$ molecule [Eq. (4)]. The main evidence comes from the similarity between the $(\Delta E, \Delta S)$ signatures of the $A$ and $B$ peaks with that of the thin films characterized by Khait $e t$ al. ${ }^{13}$ (Fig. 9 and Sec. IV A). Additionally, the experimental enthalpies have been compared with theoretical predictions by assuming that, just after the DSC peak, the energy of $\mathrm{H}_{2}$ is that of the molecule in vacuum (Sec. IV B). Of course, this is always the energy of hydrogen once outside the material; however, a long time (several minutes) elapses between the $\mathrm{SiH}$ dissociation (DSC peaks) and the detection of the $\mathrm{H}_{2}$ molecules (EGA peaks). So one may wonder whether the energy of the $\mathrm{H}_{2}$ molecule inside the sample is similar or not to that of $\mathrm{H}_{2}$ in vacuum [i.e., if $E(\mathrm{H}-\mathrm{H})_{T}$ in Eq. (4) is the dissociation energy with all species in vacuum]. In fact, the high dielectric constant of silicon would raise the energy of a $\mathrm{H}_{2}$ molecule with respect to vacuum. First-principles calculations give an increment of $0.39 \mathrm{eV}$ per $\mathrm{H}$ atom for crystalline silicon. ${ }^{55}$ If in our experiments the $\mathrm{H}_{2}$ molecules had this energy before leaving the sample, then heat would be released at the moment where the molecules leave the sample (just when they are detected). So an additional highly exothermic peak should be detected with a peak shape similar to that of the EGA signal (dashed curve in Fig. 5). This signal would be around 10 times higher than the DSC peak actually detected during $\mathrm{SiH}$ dissociation and would mask it. From the actual shape of the DSC thermograms, it is clear that the energy of the $\mathrm{H}_{2}$ molecule does not change significantly when it evolves from the sample's external surface.

An independent proof can be obtained from previous experiments on Si nanoparticles. ${ }^{20}$ In that case, no delay was observed between the DSC and EGA signals for peak $A$ and, consequently, the hydrogen state after the DSC peak is the $\mathrm{H}_{2}$ molecule in vacuum. So one would expect that the difference in the energies between the $\mathrm{H}_{2}$ molecule in vacuum and any intermediate state would increase the measured enthalpy with respect to the values reported in Table I. This is not the case: a similar enthalpy of $50 \mathrm{meV}$ was obtained. We can thus conclude that there is not an intermediate state of the $\mathrm{H}_{2}$ molecule before it leaves the sample. The hydrogen formed after dissociation of the $A, A^{\prime}$, and $B \mathrm{SiH}$ groups diffuses towards the sample surface in a molecular form that cannot be distinguished from that in a vacuum. It is transported along diffusion paths that are open in silicon nanoparticles and polymorphous silicon but are not open in the conventional device-quality material. The dehydrogenation experiments done on films deposited "on the edge of crystallinity" 6 lead one to propound that $\mathrm{H}_{2}$ out-diffusion to the sample surface (peak $B$ ) could proceed along grain boundaries created by an incipient low-temperature grain growth of the nanocrystallites. Although appealing, this explanation should be carefully complemented by independent crystallization experiments. However, our own experiments on $p m-\mathrm{Si}: \mathrm{H}$ indicate that, at the usual heating rates of the EGA thermograms $(>10 \mathrm{~K} / \mathrm{min})$, its crystallization kinetics is identical to that of conventional $a-\mathrm{Si}: \mathrm{H}$ films ${ }^{31,56}$ and no incipient crystallization related to the nanocrystals of its structure is detected.

As far as we know, our results constitute the first experimental evidence of a dominating diffusion mechanism of $\mathrm{H}$ in molecular form through the bulk of a device-quality amorphous silicon material (such as polymorphous silicon). Previous evidence of transport of $\mathrm{H}_{2}$ in amorphous silicon was reported for low-quality thin-film materials, ${ }^{16}$ where the microstructure contained a large amount of interconnected voids. In contrast, polymorphous silicon is a much denser material with a void volume fraction lower than $1 \% .{ }^{57}$

\section{E. Si-H dissociation energy}

In Sec. IV B it has become clear which are the initial and final states before and after the bond-breaking and rearranging processes and which are the individual contributions to the enthalpy of dehydrogenation [Eq. (14)]. Apart from the minor contribution of the relaxation processes $\left[E_{\text {relax }}\right.$ $<30 \mathrm{meV} /(\mathrm{H}$ atoms), Sec. IV B], Eq. (4) contains two unknowns: the dangling-bond formation energy $[E(\mathrm{DB})]$ and the dissociation energy of the $\mathrm{Si}-\mathrm{H}$ bond $\left[E_{i}(\mathrm{Si}-\mathrm{H})\right]$. We need, thus, an independent equation to determine these energies. $E_{i}(\mathrm{Si}-\mathrm{H})$ can be obtained from the analysis of the dehydrogenation kinetics.

Although in the past some doubts have arisen concerning the mechanism of dehydrogenation from surfaces of crystalline silicon $(c-\mathrm{Si}),{ }^{53}$ nowadays it is commonly agreed that it proceeds through the simultaneous formation of a $\mathrm{H}_{2}$ molecule when two neighboring $\mathrm{Si}-\mathrm{H}$ groups dissociate: ${ }^{58}$

$$
2 \mathrm{SiH} \rightarrow 2 \mathrm{Si} \cdot+\mathrm{H}_{2}, \quad(\text { Step } 1)
$$

where $\mathrm{Si} \cdot$ means a dangling bond. Recent quantum-chemistry calculations have analyzed the desorption processes from $\mathrm{Si}(100)$ surfaces and predicted energy barriers $(\approx 2.6 \mathrm{eV})$ as well as reaction orders that agree with experiment. ${ }^{58}$ The interpretation of the energy barrier is simply the energy balance of step 1 - that is, 


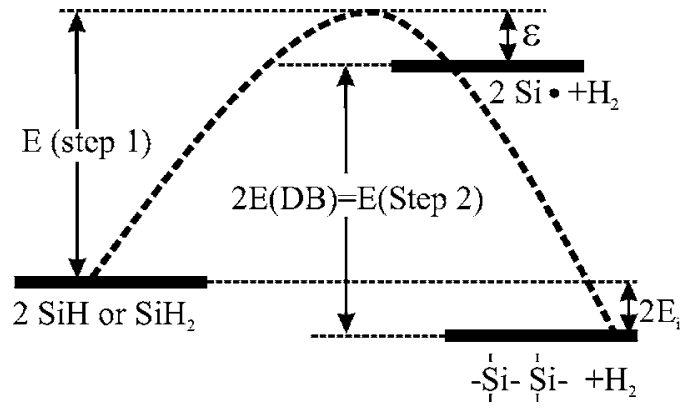

FIG. 10. Energy diagram showing the two-step reaction kinetics used to interpret the dehydrogenation processes at low temperature. From the activation energy $E$ (step 1 ) (deduced from the signature of Fig. 9) and the enthalpy of the particular process, $E_{i}$ (area of the DSC peak), it is possible to obtain the dangling-bond formation energy $[E(\mathrm{DB})]$.

$$
E(\text { step } 1)=2 E(\mathrm{Si}-\mathrm{H})_{0}-E(\mathrm{H}-\mathrm{H})_{0}+\varepsilon,
$$

where $E(\mathrm{Si}-\mathrm{H})_{0}$ and $E(\mathrm{H}-\mathrm{H})_{0}$ correspond to the transitions between the lowest-energy states of the initial and final species involved in the bond-breaking processes (i.e., they are the dissociation energies at $0 \mathrm{~K}$ ) and $\varepsilon$ accounts for any additional energy barrier between the activated state and the $\mathrm{H}_{2}$ molecule (Fig. 10). From the formation enthalpy of a $\mathrm{H}$ atom at room temperature and the enthalpy variations down to $0 \mathrm{~K},{ }^{52}$ the value of $E(\mathrm{H}-\mathrm{H})_{0}$ can be obtained $(4.476 \mathrm{eV})$. Consequently, the activation energy of hydrogen desorption, $E$ (step 1), allows the quantification of $E(\mathrm{Si}-\mathrm{H})_{0}$.

For dehydrogenation of $\mathrm{SiH}$ groups located at the surfaces of internal voids in amorphous silicon thin films (process $A^{\prime}$ ), the same mechanism was proposed. ${ }^{16}$ In this case, the lower activation energy of $1.90 \mathrm{eV}$ was tentatively explained as arising from dihydride groups. This proposal agrees with theoretical calculations ${ }^{15}$ indicating a lowering of the energy barrier when the $\mathrm{H}_{2}$ molecule is formed. Within this model, the dissociation energy of the $\mathrm{SiH}$ group of process $A^{\prime}$ was determined from EGA experiments. ${ }^{13,16}$ An additional complication that arises when dealing with $a$-Si:H materials is the fact that the energy barrier cannot be directly identified with the activation energy of the thermograms. As we have already commented in Sec. IV A and illustrated in Fig. 9, every $\mathrm{SiH}$ desorption process is characterized by a straight line relating the activation energies $(\Delta E)$ with the activation entropies $(\Delta S)$ measured for several samples. According to the interpretation given for process $A^{\prime},{ }^{13}$ the energy barrier corresponds to the activation energy when $\Delta S=0$, because, in this particular situation, no extra energy is provided by carriers to help in the bond-breaking process. This condition delivers $E($ step 1$)=1.91 \mathrm{eV}$ for process $A^{\prime}$. The similar relationship between $\Delta E$ and $\Delta S$ observed for processes $A$ and $B$ (Fig. 9) leads us to conclude that the same mechanism of dehydrogenation applies and the values $E($ step 1$)=1.80 \mathrm{eV}$ and $2.09 \mathrm{eV}$ are obtained for processes $A$ and $B$, respectively. Finally, application of Eq. (5) with $E(\mathrm{H}-\mathrm{H})_{0}=4.476 \mathrm{eV}$ allows determination of the various $\mathrm{Si}-\mathrm{H}$ dissociation energies: $E(\mathrm{Si}-\mathrm{H})_{0}=3.14 \mathrm{eV}$ (process $\left.A\right), 3.19 \mathrm{eV}\left(A^{\prime}\right)$, and $3.28 \mathrm{eV}(B)$ (Table III) which must be considered as upper bounds to the actual values because the additional barrier $\varepsilon$ has been neglected.

Since the mechanism of dehydrogenation involves the simultaneous formation of a $\mathrm{H}_{2}$ molecule, $E(\mathrm{Si}-\mathrm{H})_{0}$ is, in fact, half the energy needed to dissociate a pair of neighboring $\mathrm{SiH}$ groups. The first-principles calculations of Allan et $a l .{ }^{15}$ on $a-\mathrm{Si}: \mathrm{H}$ (Table IV) reveal that the dissociation energy of the first hydrogen atom is considerably higher than that of the second atom (Fig. 11). Their average of $3.27 \mathrm{eV}$ is very close to our experimental values, which would indicate that $\varepsilon$ is small compared to the activation energy $E$ (step 1). To confirm that this approximation is correct, theoretical calculations of the reaction paths leading to $\mathrm{Si}-\mathrm{H}$ bond breaking and $\mathrm{H}_{2}$ formation would be necessary. These kinds of analyses are very computationally intensive, which explains why, at present, theoretical predictions of $\varepsilon$ are not available. Finally, our dissociation energies are also similar to the energy needed to break the first two $\mathrm{Si}-\mathrm{H}$ bonds of a silane molecule, $3.27 \mathrm{eV}$ per bond (see Fig. 11). ${ }^{59}$

Before finishing this section, we must say that moleculardynamics simulations of the dehydrogenation process from nanocrystalline silicon (process $B$ ) (Ref. 47) predict the formation of $\mathrm{H}_{2}$ molecules. However, they do not make clear whether the molecules are formed simultaneously with the breaking of the $\mathrm{Si}-\mathrm{H}$ groups. From the characteristic signature of Fig. 9 we conclude that this is clearly the case.

\section{F. Dangling-bond formation energy}

Once the $\mathrm{Si}-\mathrm{H}$ dissociation energy has been obtained, Eq. (4) allows us to determine the energy released when a pair of dangling bonds recombines $[2 E(\mathrm{DB})]$. This process is

TABLE III. Summary of the main quantitative results obtained in the present study: enthalpy of dehydrogenation, $E$; energy barrier for dehydrogenation, $\Delta E_{0}$; $\mathrm{Si}-\mathrm{H}$ dissociation energy $E(\mathrm{Si}-\mathrm{H})_{0}($ at $0 \mathrm{~K})$; dangling-bond formation energy $E(\mathrm{DB})$ (at $300-500^{\circ} \mathrm{C}$ ).

\begin{tabular}{llcccc}
\hline \hline $\begin{array}{c}\text { Dehydrogenation } \\
\text { process }\end{array}$ & $\mathrm{Si}-\mathrm{H}$ group & $\begin{array}{c}E \\
{[\mathrm{meV} /(\mathrm{H} \text { atoms })]}\end{array}$ & $\begin{array}{c}\Delta E_{0} \\
(\mathrm{eV})\end{array}$ & $\begin{array}{c}E(\mathrm{Si}-\mathrm{H})_{0} \\
(\mathrm{eV})\end{array}$ & $\begin{array}{c}E(\mathrm{DB}) \\
(\mathrm{eV})\end{array}$ \\
\hline$A$ & Polymeric & 20 & 1.80 & 3.14 & 0.97 \\
$A^{\prime}$ & Internal voids & 50 & 1.91 & 3.19 & 1.05 \\
$B$ & At interfaces & 35 & 2.09 & 3.28 & 1.12 \\
$C$ & In bulk & 40 & & & $>1.1$ \\
\hline \hline
\end{tabular}


TABLE IV. Theoretical predictions that have been compared with our experimental results of Table III throughout the paper (enthalpies $E$ are endothermic). Notes: Except those of Allan et al., all values have been corrected by the zero-point energy. From that paper, it is not clear whether their reported values have been corrected or not.

\begin{tabular}{|c|c|c|c|c|c|}
\hline Defect & $\begin{array}{c}E^{\mathrm{a}} \\
{[\mathrm{meV} /(\mathrm{H} \text { atoms })]}\end{array}$ & $\begin{array}{l}\Delta E_{0} \\
(\mathrm{eV})\end{array}$ & $\begin{array}{l}E(\mathrm{Si}-\mathrm{H})_{0} \\
(\mathrm{eV})\end{array}$ & $\begin{array}{l}E(\mathrm{DB})^{\mathrm{a}} \\
(\mathrm{eV})\end{array}$ & Reference \\
\hline$=\mathrm{SiH}_{2}$ & -120 & 2.05 & 3.28 & 0.9 & Allan et al. (Ref. 15) \\
\hline $\mathrm{SiH}-\mathrm{SiH}$ & -100 & 2.00 & 3.26 & 1.0 & \\
\hline$\equiv \mathrm{SiH}$ & -140 & & 3.63 & 1.2 & \\
\hline Dangling bond & & & & 0.6 and 1.1 & Kelires and Tersoff (Ref. 62) \\
\hline $\begin{array}{l}\text { Dangling bond in } \\
\qquad c-\mathrm{Si}\end{array}$ & & & & 1.38 & $\begin{array}{l}\text { van de Walle } \\
\text { (Ref. 55) }\end{array}$ \\
\hline $\begin{array}{l}\text { Dangling bond in } \\
\qquad \operatorname{Si}(111)\end{array}$ & & & & 1.46 & \\
\hline Vacancy $c$-Si & & & & 0.88 & Tuttle and Adams (Ref. 64) \\
\hline Vacancy $c-\mathrm{Si}$ & & & & $0.9-1.25$ & Wang et al. (Ref. 65) \\
\hline$\equiv \mathrm{SiH}$ isolated & & & 3.30 & $1.10^{\mathrm{b}}$ & Fedders (Ref. 50) \\
\hline $\begin{array}{l}\text { SiH clustered } \\
\text { strongly bonded }\end{array}$ & & & 3.58 & $1.36^{\mathrm{b}}$ & \\
\hline $\begin{array}{l}\text { SiH clustered } \\
\text { weakly bonded }\end{array}$ & -210 & & & & \\
\hline
\end{tabular}

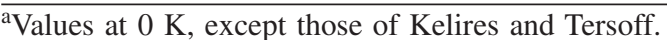

'Obtained from Fedders' $E(\mathrm{Si}-\mathrm{H})_{0}$ theoretical values and our dehydrogenation enthalpy (exothermic) of $40 \mathrm{meV} /(\mathrm{H}$ atoms) (process $C$ : see text).

just the inverse of the dangling-bond creation. So $2 E(\mathrm{DB})$ can be interpreted as the energy needed for the creation of a pair of dangling bonds. If we neglect the contribution of the Si network relaxation $\left(E_{\text {relax }}\right)$ and consider that all dangling bonds created after the dissociation of the $\mathrm{SiH}$ groups recombine $(\eta=1)$ (Sec. IV B) the calculation through application of Eq. (4) is straightforward.

For the dehydrogenation enthalpy we take the average value of all samples, excluding the conventional $a-\mathrm{Si}: \mathrm{H}$ film. The dissociation enthalpies of the $\mathrm{SiH}$ groups and $\mathrm{H}_{2}$ molecule at the dehydrogenation temperature can be calculated from their values at $0 \mathrm{~K}$ plus the contribution of "thermal" energies (vibrational and kinetic). Up to $800 \mathrm{~K}$, the $\mathrm{H}_{2}$ dissociation enthalpy is given within an accuracy of $1 \mathrm{meV}$ (Ref. 52) by the formula

a)
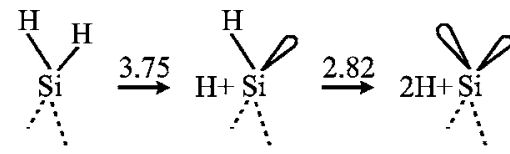<smiles></smiles><smiles>C[Si](C)(C)[SiH2][SiH3]</smiles><smiles>C[Si]1(C)CO1</smiles>

b)

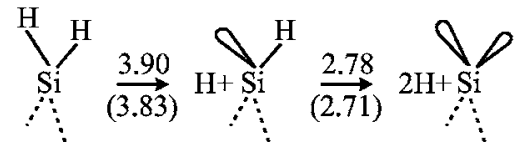

FIG. 11. (a) Dissociation energies of several $\mathrm{SiH}$ groups in $a$ -Si:H obtained from semiempirical calculations (Ref. 15). (b) Dissociation energy of the first two $\mathrm{H}$ atoms in a silane molecule obtained by Walsh (Ref. 59) from experimental standard enthalpies of formation (in brackets, values corrected to $0 \mathrm{~K}$ ).

$$
E(\mathrm{H}-\mathrm{H})_{T}=E(\mathrm{H}-\mathrm{H})_{0}+\frac{3}{2} k T
$$

where $\frac{3}{2} k T$ is of the order of $80-100 \mathrm{meV}$ in the temperature range of interest $\left(300-500{ }^{\circ} \mathrm{C}\right)$. Concerning the $\mathrm{Si}-\mathrm{H}$ bond, its dissociation enthalpy at finite temperature increases with respect to the $0 \mathrm{~K}$ value, too, because the vibrational energy of the $\mathrm{Si}-\mathrm{H}$ bond, $\Delta U(\mathrm{vib})_{T}$, is lower than the enthalpy increment of the $\mathrm{H}$ atom $\left(\frac{5}{2} k T\right)$ :

$$
E(\mathrm{Si}-\mathrm{H})_{T}=E(\mathrm{Si}-\mathrm{H})_{0}-\Delta U(\mathrm{vib})_{T}+\frac{5}{2} k T .
$$

The vibrational energy is given by the Einstein theory of specific heat: 60

$$
\Delta U(\mathrm{vib})_{T}=\sum_{\mu} g_{\mu} \frac{\hbar \omega_{\mu}}{\exp \left(\hbar \omega_{\mu} / k T\right)-1},
$$

where the summation extends over the vibrational modes of frequencies $\omega_{\mu}$ with degeneracy $g_{\mu}$. Since no significant differences exist among different $\mathrm{SiH}$ groups, ${ }^{55}$ the calculation of $\Delta U(\mathrm{vib})_{T}$ will be done for the $\mathrm{SiH}$ group on a $\mathrm{Si}(111)$ surface. It has a nondegenerate stretching mode at $2080 \mathrm{~cm}^{-1}$ and a doubly degenerate wagging mode at $630 \mathrm{~cm}^{-1}$. The overall "thermal" contribution to the $\mathrm{Si}-\mathrm{H}$ dissociation enthalpy is also $80-100 \mathrm{meV}$, in the temperature range of interest.

Now, the introduction of the dissociation and dehydrogenation enthalpies in Eq. (4) delivers $E(D B)=0.97,1.05$, and $1.12 \mathrm{eV}$ for the dangling bonds created during processes $A$, $A^{\prime}$, and $B$, respectively (Table III). [Our previous determination for peak $A$ in nanoparticles of (1.04 eV) (Ref. 20) was 
less accurate because, at that time, we were not able to build the signature of this particular process for nanoparticles and considered that it was the same as the $A^{\prime}$ process in thin films.] Similarly to the case of the $\mathrm{SiH}$ energy ( $\mathrm{Sec}$. IV E), the actual value of $E(\mathrm{DB})$ is, in fact, lower by $\varepsilon / 2$ than the quoted values. However, in the absence of any theoretical or experimental estimation of $\varepsilon$, we consider it to be negligible.

Let us pay attention to the dependence of $E(\mathrm{DB})$ on the particular $\mathrm{SiH}$ group. The hydrogen in polymeric chains (peak $A$ ) corresponds to a less-confined state than hydrogen on the surfaces of internal voids (peak $A^{\prime}$ ). Presumably, the degree of confinement is even higher for peak $B$ because its kinetics has always been found to be diffusion controlled. ${ }^{20,41}$ Our results indicate, thus, that the danglingbond energy is higher when it becomes more confined. This means that one would expect a formation energy for an isolated dangling bond in bulk (peak $C$ ) higher than $1.10 \mathrm{eV}$. This conclusion is useful because calculations ${ }^{15,61,62}$ try to simulate this particular dangling-bond defect. In addition, this is the kind of dangling bond that presumably accounts for the defect density in device-quality materials. ${ }^{63}$

A number of theoretical works devoted to predicting the formation energy of a dangling bond have been published (Table IV). They provide a very disperse set of values ranging from 0.6 to $1.2 \mathrm{eV}$. The first attempt was made by Allan et al., ${ }^{15}$ whose values of 0.9 and $1.0 \mathrm{eV}$ for neighboring dangling bonds and $1.2 \mathrm{eV}$ for isolated dangling bonds agree reasonably well with our experimental results (0.97-1.12 and $>1.10 \mathrm{eV}$, respectively). Furthermore, they provide additional support for the dependence of the dangling-bond energy with the degree of confinement. In contrast, a much smaller value of $0.6 \mathrm{eV}$ was obtained by Kelires and Tersoff $^{62}$ for the three coordinated atoms that form in $a$-Si after rapid quenching from the liquid state. In this case, the reliability can be judged from the fact that the same authors obtained an energy of $1.1 \mathrm{eV}$ when using an alternative interaction potential. ${ }^{62}$ On the other hand, the calculations of van de Walle ${ }^{55}$ for crystalline silicon delivered 1.38 and $1.46 \mathrm{eV}$ for the isolated dangling bond in bulk or on a $\mathrm{Si}(111)$ surface, respectively. Following the author's opinion, ${ }^{61}$ these values are unphysically large for $a$-Si and would be incompatible with results of hydrogen diffusion. Although our values do diminish, they are not as low as expected, ${ }^{61}$ thus providing an additional constraint to the current models of hydrogen diffusion.

From other theoretical calculations we can extract straightforward predictions of the dangling-bond energy in bulk. First, a number of authors have calculated the formation energy of a vacancy in crystalline silicon ${ }^{64,65}$ and obtained values ranging from 3.6 to $5.0 \mathrm{eV}$, which correspond to $0.9-1.25 \mathrm{eV}$ per DB of the vacancy. Second, from realistic $a-\mathrm{Si}: \mathrm{H}$ supercells, Fedders ${ }^{50}$ has obtained $E(\mathrm{Si}-\mathrm{H})_{0}$ $=3.30$ and $3.58 \mathrm{eV} /(\mathrm{H}$ atoms $)$ for isolated and strongly bonded clustered $\mathrm{Si}-\mathrm{H}$ groups in bulk. Application of Eq. (4) with a dehydrogenation enthalpy (exothermic) of $40 \mathrm{meV} /(\mathrm{H}$ atoms $)$ (see Sec. IV $\mathrm{H})$ delivers $E(\mathrm{DB}) \approx 1.10$ and $1.37 \mathrm{eV}$, respectively (Table IV).

From the experimental point of view, the only estimation of the dangling-bond formation energy comes from the analysis of the density of dangling bonds in $a-\mathrm{Si}: \mathrm{H} .{ }^{63}$ In the classic paper by Smith and Wagner, ${ }^{63}$ the authors use a value of $0.85 \mathrm{eV}$ to fit the density of defects. Our prediction for the isolated dangling bond is clearly higher $(>1.10 \mathrm{eV})$. We think that our value is more reliable for several reasons. First, the predicted defect density in equilibrium at the growth temperature depends critically on the particular microscopic model of defect reaction with hydrogen atoms leading to dangling-bond creation and annihilation. ${ }^{66}$ So the particular model used by Smith and Wagner may not be the main one. Second, in their particular analysis, they identify the formation energy of a dangling bond with the energy needed to promote an electron from the valence band to the empty acceptor level. This identification is clearly an approximation because it neglects the effect that a change of the charge state has on the energy of the core electrons of the threefoldcoordinated silicon atom.

Finally, the values we have obtained should be compared to the energy of formation of monatomic Si gas $[1.16 \mathrm{eV} /(\mathrm{Si}$ atoms)]. ${ }^{52}$

\section{G. High-temperature dehydrogenation of $\mathrm{SiH}$ groups in bulk}

In both $p m-\mathrm{Si}: \mathrm{H}$ and $a-\mathrm{Si}: \mathrm{H}$ samples, a dehydrogenation process occurs above $500{ }^{\circ} \mathrm{C}$ (process $C$, Fig. 1). It corresponds to $\mathrm{SiH}$ groups in the bulk of the silicon network, and its kinetics is controlled by $\mathrm{H}$ diffusion. In fact, for thin enough samples ${ }^{17}$ the activation energy of the EGA peak is just that of the $\mathrm{H}$ diffusivity. Following the most widely accepted model of $\mathrm{H}$ diffusion in $a$-Si: $\mathrm{H},{ }^{4,67} \mathrm{H}$ atoms are transported between lattice sites where they become trapped and released. This means that $\mathrm{SiH}$ groups in bulk are continuously created and dissociated until the $\mathrm{H}$ atoms reach the sample's surface where $\mathrm{H}_{2}$ molecules are formed by a surface desorption process similar to those occurring at lower temperature. This picture implies that, in contrast with the low-temperature processes, for process $C$ there is not a single $\mathrm{SiH}$ dissociation step and, consequently, the method used in $\mathrm{Sec}$. IV $\mathrm{E}$ for determining the $\mathrm{Si}-\mathrm{H}$ dissociation energy from the DSC curve cannot be applied. Unfortunately, our measurements do not allow us to determine this quantity.

The rest of this section will be devoted to analyzing the values of the enthalpy $\left(E_{C}\right.$ in Table I). For the polymorphous sample $E_{C}[\approx 40 \mathrm{meV} /(\mathrm{H}$ atoms $)]$ is similar to the enthalpies of the low-temperature processes. However, this value is much higher $\left[E_{C} \approx 700 \mathrm{meV} /(\mathrm{H}\right.$ atoms $\left.)\right]$ for the conventional amorphous sample. This apparent discrepancy can be explained by a structural relaxation.

The contribution of relaxation phenomena to the enthalpy of the low-temperature processes has been already discussed in Sec. IV B. We argued there that for those particular $\mathrm{SiH}$ groups, the corresponding term, $E_{\text {relax }}$ in Eq. (4), was small and that it could explain the variations of several tens of $\mathrm{meV}$ from sample to sample and for different heating rates. Additionally, we can say that, after $\mathrm{Si}-\mathrm{H}$ bond breaking, little relaxation occurs due to the transport of molecular hydrogen because, as discussed in Sec. IV D, the interaction of the $\mathrm{H}_{2}$ molecule with the silicon network is negligible. The situation is very different for peak $C$ because hydrogen diffuses in atomic form. In his way, $\mathrm{Si}-\mathrm{H}$ bonds are continu- 
ously broken and created, thus favoring relaxation phenomena such as anihilation of strained $\mathrm{Si}-\mathrm{Si}$ bonds.

Within this framework, the amount of energy released per unit time due to relaxation will depend on (a) the random walk displacements of the $\mathrm{H}$ atoms through the Si network and (b) the particular state of the Si network at the beginning of process $C$. Thus, the random walk of $\mathrm{H}$ atoms has two effects: a release of energy and the diffusion of $\mathrm{H}$ atoms to the surface. This fact explains why the thermal and EGA signals of peak $C$ are detected at the same temperature range (compare the curves of $a$-Si in Figs. 1 and 3). On the other hand, the state of the silicon network explains why process $C$ is much more exothermic in conventional material than in polymorphous $\mathrm{Si}$. Two facts can justify a higher relaxation in the conventional material: (1) structural analyses have revealed that, in the as-grown state, polymorphous silicon is a more relaxed material ${ }^{29}$ and (2) from the DSC thermograms of Fig. 3, it is clear that the $\mathrm{pm}-\mathrm{Si}: \mathrm{H}$ sample has experienced a higher relaxation during the heating ramp up to $500{ }^{\circ} \mathrm{C}$. Consequently, the $a-\mathrm{Si}: \mathrm{H}$ sample reaches the onset of hightemperature dehydrogenation with a higher amount of energy stored in the Si network. We consider, then, that the enthalpy obtained from the polymorphous sample is close to the energy of the $\mathrm{SiH}$ groups in bulk whereas the difference with the enthalpy of the $a-\mathrm{Si}: \mathrm{H}$ sample $[\approx 650 \mathrm{meV} /(\mathrm{H}$ atoms $)]$ is due to lattice relaxation. This interpretation is reinforced by the fact that at a heating rate of $40 \mathrm{~K} / \mathrm{min}$ the pronounced exothermic band in $a$-Si:H disappears. ${ }^{31} \mathrm{In}$ other words, the difference observed in Fig. 3 between $p m-\mathrm{Si}: \mathrm{H}$ and $a-\mathrm{Si}: \mathrm{H}$ is not due to different $\mathrm{SiH}$ groups in bulk but to the contribution of relaxation processes.

The heat released in $a$-Si: $\mathrm{H}$ during process $C$ gives strong evidence that extensive relaxation occurs due to the movement of $\mathrm{H}$ atoms. This relationship was deduced in a more indirect way from the evolution of the $\mathrm{H}$ diffusivity ${ }^{68}$ or material density ${ }^{69}$ during long annealing times. Comparison of our EGA and DSC curves for $a$-Si: $\mathrm{H}$ sample (Figs. 1 and 3 ) indicates that relaxation occurs simultaneously with the dehydrogenation process $C$. It does not require long periods of thermal annealing.

Finally, let us note that the heat released per $\mathrm{H}$ atom is very high: $700 \mathrm{meV} /(\mathrm{H}$ atoms $)$ is more than one-half of the dangling-bond formation energy. When $\mathrm{H}$ transport proceeds, the network topology changes and evolves towards a less-strained configuration. In particular, a significant diminution of the density of weak $\mathrm{Si}-\mathrm{Si}$ bonds will occur and, after release of the $\mathrm{H}$ atoms trapped in the deeper levels, recombination of isolated dangling bonds is expected. Both weak bonds and dangling bonds act as traps for $\mathrm{H}^{4}$ Given our results, it is doubtful to assume that the density of traps remains unchanged during $\mathrm{H}$ diffusion. ${ }^{18,67} \mathrm{In}$ fact, the assumption of constant trap density relies on very particular experiments ${ }^{4}$ where samples were annealed (and thus relaxed) before post-hydrogenation experiments. Under these conditions the Si network is presumably much more stable than in most diffusion experiments carried out on as-grown films. ${ }^{17,18,70}$

\section{CONCLUSIONS}

Application of differential scanning calorimetry to the analysis of dehydrogenation processes in amorphous silicon materials affords new information (the thermal signal) that cannot be obtained by the vast number of techniques that are currently used to elucidate the microscopic processes involved (a summary of the main numerical results is given in Table III which can be compared with the theoretical predictions collected in Table IV). In addition to the direct quantification of the enthalpy, the heat exchanged, as well as its thermal activation, allows determination of the energies related to elementary bond-breaking $(\mathrm{Si}-\mathrm{H}$ dissociation) and rearranging processes (dangling-bond recombination). Secondary effects induced by dehydrogenation such as lattice relaxation can also be easily detected on time scales much shorter than the experiments already reported in the literature. The lack of any delay between bond breaking and the thermal signal makes it possible to identify the various dehydrogenation processes and their correspondence among different materials. This correspondence has usually remained doubtful when based on the temperature of the $\mathrm{H}$-evolution bands detected by mass spectrometry.

These possibilities have been extensively explored in the present paper, which constitutes a very complete calorimetric study of hydrogenated amorphous silicon. We hope that our contribution will promote future applications of calorimetry to the analysis of other structural transformations in this material.

Note added in proof. Recent experiments of dehydrogenation at room temperature induced by light soaking ${ }^{71}$ reinforce the interpretation of molecular diffusion in $p m-\mathrm{Si}: \mathrm{H}$ and even in $a-\mathrm{Si}: \mathrm{H}$ after the bond breaking of the $A, A^{\prime}$, and $B$ $\mathrm{Si}-\mathrm{H}$ groups. Once the light is turned off, hydrogen continues to evolve from the sample during a long period of time (several tens of minutes). If hydrogen diffused in atomic form, without photons no energy would be available to break its bond to the $\mathrm{Si}$ atoms and it would remain trapped inside the sample. Furthermore, the diffusivity at room temperature $\left(>5 \times 10^{-14} \mathrm{~cm}^{2} / \mathrm{s}\right)$ is, at least, five orders of magnitude higher than the upper bound of the atomic diffusivity values ${ }^{4}$ indicating that the transport mechanism is different.

\section{ACKNOWLEDGMENTS}

This work has been supported by the Spanish "Programa Nacional de Materiales" under Contracts No. MAT-200204236-C04-02 and No. MAT-2002-04236-C04-04. One of the authors (C.R.) wishes to acknowledge the Ministerio de Ciencia y Tecnología, Government of Spain, for support.

\section{APPENDIX: THERMAL ACTIVATION OF THE PEAK TEMPERATURE FOR FIRST-ORDER KINETICS}

Consider that the kinetic constant $K$ is thermally activated with an activation energy $\Delta E$ and proportional to the absolute temperature $T$ through the attempt frequency $k T / h$ :

$$
K=\left(K^{\prime} T\right) e^{-\Delta E / k T},
$$

where $K^{\prime}$ is temperature independent. For first-order kinetics, the transformation rate will be given by 


$$
r(t) \equiv \frac{d n}{d t}=-K n,
$$

where $n$ is the untransformed fraction. During a heating ramp at constant rate $\beta \equiv d T / d t$, the transformation rate will pass through a maximum value at the peak temperature $T_{M}$. Derivation of $r$ allows the determination of $T_{M}$ :

$$
\left.\frac{d r}{d T}\right|_{T_{M}}=\left.\frac{d r}{d t} \frac{1}{\beta}\right|_{T_{M}}=0 .
$$

Substitution of Eqs. (A1) and (A2) into Eq. (A3) leads to the exact relationship

$$
e^{-\Delta E / k T_{M}}=\frac{\beta}{T_{M}^{3}} \frac{\Delta E}{k K^{\prime}}\left(1+\frac{k T_{M}}{\Delta E}\right) .
$$

Now, in most cases $k T / \Delta E \ll 1$ and the term closed in brackets can be approximated by $e^{k T / \Delta E}$. This approximation leads, after a little algebra, to the desired result

$$
\ln \frac{\beta}{T_{M}^{3}}=\ln \frac{k K^{\prime}}{\Delta E}-\frac{\Delta E}{k T_{M}},
$$

which allows determination of the activation energy $\Delta E$ and the temperature-independent preexponential constant $K^{\prime}$ from a Kissinger plot $\left[\ln \left(\beta / T^{3}\right)\right.$ vs $\left.1000 / T\right]$.
${ }^{1}$ R. A. Street, Hydrogenated Amorphous Silicon (Cambridge University Press, Cambridge, England, 1991).

${ }^{2}$ K. Zellama, L. Chahed, P. Sládek, M. L. Thèye, J. H. von Bardeleben, and P. Roca i Cabarrocas, Phys. Rev. B 53, 3804 (1996).

${ }^{3}$ M. Cardona, Phys. Status Solidi B 118, 463 (1983).

${ }^{4}$ W. B. Jackson and C. C. Tsai, Phys. Rev. B 45, 6564 (1992).

${ }^{5}$ S. Lebib and P. Roca i Cabarrocas, Eur. Phys. J.: Appl. Phys. 26, 17 (2004).

${ }^{6}$ A. H. Mahan, W. Beyer, D. L. Williamson, J. Yang, and S. Guha, Philos. Mag. Lett. 80, 647 (2000).

${ }^{7}$ J. B. Boyce and M. Stutzmann, Phys. Rev. Lett. 54, 562 (1985).

${ }^{8}$ P. A. Fedders, D. J. Leopold, P. H. Chan, R. Borzi, and R. E. Norberg, Phys. Rev. Lett. 85, 401 (2000).

${ }^{9}$ S. Oguz and M. A. Paesler, Phys. Rev. B 22, 6213 (1980).

${ }^{10}$ M. H. Brodsky, M. A. Fisch, J. F. Ziegler, and W. A. Lanford, Appl. Phys. Lett. 30, 561 (1977).

${ }^{11}$ W. Beyer and H. Wagner, J. Non-Cryst. Solids 59, 161 (1983).

${ }^{12}$ D. K. Biegelsen, R. A. Street, C. C. Tsai, and J. C. Knights, Phys. Rev. B 20, 4839 (1979).

${ }^{13}$ Yu. L. Khait, R. Weil, R. Beserman, W. Beyer, and H. Wagner, Phys. Rev. B 42, 9000 (1990).

${ }^{14}$ K. P. Huber, in AIP Handbook of Physics, edited by D. E. Grey (McGraw-Hill, New York, 1972), Chap. 7, p. 168.

${ }^{15}$ D. C. Allan, J. D. Joannopoulos, and W. B. Pollard, Phys. Rev. B 25, 1065 (1982).

${ }^{16}$ W. Beyer, Physica B 170, 105 (1991).

${ }^{17}$ W. Beyer and H. Wagner, J. Appl. Phys. 53, 8745 (1982).

${ }^{18}$ S. Acco, W. Beyer, E. E. van Faassen, and W. F. van der Weg, J. Appl. Phys. 82, 2862 (1997).

${ }^{19}$ H. M. Branz, Phys. Rev. B 60, 7725 (1999).

${ }^{20}$ J. Farjas, D. Das, J. Fort, P. Roura, and E. Bertran, Phys. Rev. B 65, 115403 (2002).

${ }^{21}$ L. Battezzati, F. Demichelis, C. F. Pirri, and E. Tresso, Physica B 176, 73 (1992).

${ }^{22}$ L. Battezzati, F. Demichelis, C. F. Pirri, and E. Tresso, J. Appl. Phys. 69, 2029 (1991).

${ }^{23}$ B. G. Budaguan, A. A. Aivazov, M. N. Meytin, A. Yu. Sazonov, and J. W. Metselaar, Physica B 252, 198 (1998).

${ }^{24}$ S. M. Lee, S. J. Jones, Y.-M. Li, W. A. Turner, and W. Paul, Philos. Mag. B 60, 547 (1989).

${ }^{25}$ R. Butté, R. Meaudre, M. Meaudre, S. Vignoli, C. Longeaud, J. P.
Kleider, and P. Roca i Cabarrocas, Philos. Mag., Suppl. 79, 1079 (2003).

${ }^{26}$ J. P. Kleider, C. Longeaud, M. Gauthier, M. Meaudre, R. Meaudre, R. Butté, S. Vignoli, and P. Roca i Cabarrocas, Appl. Phys. Lett. 75, 3351 (1999).

${ }^{27}$ S. Tchakarov, P. Roca i Cabarrocas, U. Dutta, P. Chatterjee, and E. Equer, J. Appl. Phys. 94, 7317 (2003).

${ }^{28}$ Y. Poissant, P. Chatterjee, and P. Roca i Cabarrocas, J. Appl. Phys. 94, 7305 (2003).

${ }^{29}$ A. Fontcuberta i Morral, H. Hofmeister, and P. Roca i Cabarrocas, J. Non-Cryst. Solids 299-302, 284 (2002).

${ }^{30}$ A. H. Mahan, J. Yang, S. Guha, and D. L. Williamson, Phys. Rev. B 61, 1677 (2000).

${ }^{31}$ Chandana Rath, J. Farjas, P. Roura, F. Khail, P. Roca i Cabarrocas, and E. Bertran, J. Mater. Res. 20, 2562 (2005).

${ }^{32}$ E. Bertran, J. Costa, G. Sardin, J. Campmany, J. L. Andujar, and A. Canillas, Plasma Sources Sci. Technol. 3, 348 (1994).

${ }^{33}$ J. Costa, G. Sardin, J. Campmany, and E. Bertran, in Amorphous Silicon Technology-1993, edited by E. A. Schiff et al., Mater. Res. Soc. Symp. Proc. No. 297 (Materials Research Society, Pittsburgh, 1993), p. 1031.

${ }^{34}$ G. Viera, M. Mikikian, E. Bertran, P. Roca i Cabarrocas, and L. Boufendi, J. Appl. Phys. 92, 4684 (2002).

${ }^{35}$ D. Das, J. Farjas, P. Roura, J. Viera, and E. Bertran, Appl. Phys. Lett. 79, 3705 (2001).

${ }^{36}$ S. Roorda, S. Doorn, W. C. Sinke, P. M. L. O. Scholte, and E. van Loenen, Phys. Rev. Lett. 62, 1880 (1989).

${ }^{37}$ S. Roorda, W. C. Sinke, J. M. Poate, D. C. Jacobson, S. Dierker, B. S. Dennis, D. J. Eaglesham, F. Spaepen, and P. Fuoss, Phys. Rev. B 44, 3702 (1991).

${ }^{38}$ P. A. Redhead, Vacuum 12, 203 (1962).

${ }^{39}$ R. A. Street, C. C. Tsai, J. Kakalios, and V. B. Jackson, Philos. Mag. B 56, 305 (1987).

${ }^{40}$ Y. L. Khait, A. Silverman, R. Weil, and J. Adler, Phys. Rev. B 44, 8308 (1991).

${ }^{41}$ J. Costa, J. Fort, J. J. Sunyol, P. Roura, G. Viera, and E. Bertran, in Hydrogen in Semiconductors and Metals, edited by N. H. Nickel, W. B. Jackson, and R. C. Bowman, Mater. Res. Soc. Symp. Proc. No. 513 (Materials Research Society, Pittsburgh, 1997), p. 427.

${ }^{42}$ J. Costa, G. Sardin, J. Campmany, J. L. Andujar, A. Canillas, and E. Bertran, in Amorphous Silicon Technology_1993, edited by 
E. A. Schiff et al., Mater. Res. Soc. Symp. Proc. No. 297 (Materials Research Society, Pittsburgh, 1993), p. 1031.

${ }^{43}$ G. Lucovsky, R. J. Nemanich, and J. C. Knights, Phys. Rev. B 19, 2064 (1979).

${ }^{44}$ Y. J. Chabal, G. S. Higashi, K. Raghavachari, and V. A. Burrows, J. Vac. Sci. Technol. A 7, 2104 (1989).

${ }^{45}$ S. Agarwal, A. Takano, M. C. M. Sanden, D. Maroudas, and E. S. Aydil, J. Chem. Phys. 117, 10805 (2002).

${ }^{46}$ S. Lebib and P. Roca i Cabarrocas, J. Appl. Phys. 97, 104334 (2005).

${ }^{47}$ B. C. Pan and R. Biswas, J. Non-Cryst. Solids 333, 44 (2004).

${ }^{48}$ W. Paul, S. J. Jones, and W. A. Turner, Philos. Mag. B 63, 247 (1991).

${ }^{49}$ Heat-flux commercial DSC (TA Instruments).

${ }^{50}$ P. A. Fedders, Phys. Rev. B 64, 165206 (2001).

${ }^{51}$ W. B. Jackson and C. C. Tsai, Phys. Rev. B 45, 6564 (1992).

${ }^{52}$ CRC Handbook of Chemistry and Physics, 81st ed. (CRC Press, Boca Raton, FL, 2001).

${ }^{53}$ W. R. Wampler, S. M. Myers, and D. M. Follstaedt, Phys. Rev. B 48, 4492 (1993).

${ }^{54}$ J. B. Boyce and S. E. Ready, Physica B 170, 305 (1991).

${ }^{55}$ C. G. Van de Walle, Phys. Rev. B 49, 4579 (1994).

${ }^{56}$ J. Farjas, J. Serra-Miralles, P. Roura, P. Roca i Cabarrocas, and E. Bertran, J. Mater. Res. 20, 277 (2005).

${ }^{57}$ A. Fontcuberta i Morral, P. Roca i Cabarrocas, and C. Clerc,
Phys. Rev. B 69, 125307 (2004).

${ }^{58}$ C. Mui, S. F. Bent, and C. B. Musgrave, J. Phys. Chem. B 108, 18243 (2004).

${ }^{59}$ R. Walsh, Acc. Chem. Res. 14, 246 (1981).

${ }^{60}$ J. I. Gersten and F. W. Smith, The Physics and Chemistry of Materials (Wiley, New York, 2001), Chap. V.

${ }^{61}$ C. G. Van de Walle and R. A. Street, Phys. Rev. B 51, 10615 (1995).

${ }^{62}$ P. C. Kelires and J. Tersoff, Phys. Rev. Lett. 61, 562 (1988).

${ }^{63}$ Z. E. Smith and S. Wagner, Phys. Rev. Lett. 59, 688 (1987).

${ }^{64}$ B. Tuttle and J. B. Adams, Phys. Rev. B 57, 12859 (1998).

${ }^{65}$ C. Z. Wang, C. T. Chan, and K. M. Ho, Phys. Rev. Lett. 66, 189 (1991), and references therein.

${ }^{66}$ R. A. Street and K. Winer, Phys. Rev. B 40, 6236 (1989).

${ }^{67}$ A. J. Franz, M. Mavrikakis, and J. L. Gland, Phys. Rev. B 57, 3927 (1998).

${ }^{68}$ S. Mitra, R. Shinar, and J. Shinar, Phys. Rev. B 42, R6746 (1990).

${ }^{69}$ Z. Remes, M. Vanecek, A. H. Mahan, and R. S. Crandall, Phys. Rev. B 56, R12710 (1997).

${ }^{70}$ K. Zellama, P. Germain, S. Squelard, B. Bourdon, J. Fontenille, and R. Danielou, Phys. Rev. B 23, 6648 (1981).

${ }^{71}$ F. Kail, S. Fellah, A. Abramov, A. Hadjadj, and P. Roca i Cabarrocas, J. Non-Cryst. Solids (to be published). 